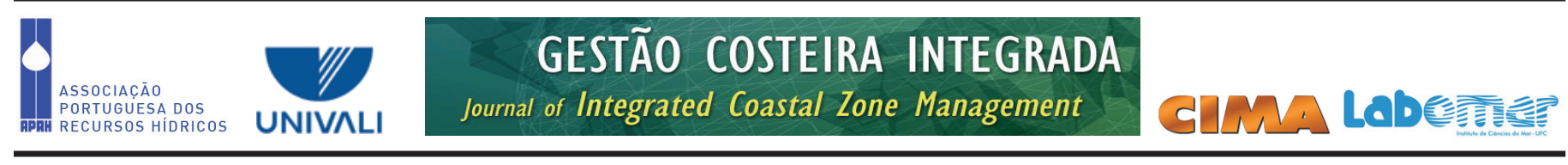

http://www.aprh.pt/rgci/pdf/rgci-378_Matos.pdf | DOI:10.5894/rgci378

\title{
Análise Comparativa da Agitação Obtida com o Modelo Numérico (SWAN) na Modelagem de Ondas do Litoral Setentrional do Rio Grande do Norte, Brasil e Dados de Campo *
}

\section{Comparative Analysis of Agitation Obtained the Numeric Model (SWAN) in Modeling Rio Grande do Norte (Brazil) Northern Coastal Waves and Field Data}

\author{
Maria de Fátima Alves de Matos ${ }^{\circledR, 1}$, Conceição Juana E.M. Fortes ${ }^{2}$, Venerando Eustáquio Amaro ${ }^{1}$, \\ Ada Cristina Scudelari ${ }^{1}$
}

\section{RESUMO}

Este artigo visa apresentar as análises comparativas da agitação marítima entre as mediçóes obtidas dos resultados da modelagem numérica, com a aplicação do modelo SWAN, e os resultados das mediçóes in situ durante duas campanhas realizadas no período de 20 a 27 de dezembro de 2010 e de 15 a 22 de fevereiro de 2011, na costa do litoral setentrional do Rio Grande do Norte, Nordeste do Brasil. O estudo tem como principal objetivo, avaliar o desempenho do modelo SWAN quanto à previsão de agitação marítima, aferindo suas potencialidades e limitaçóes para a região de interesse.

As mediçóes in situ foram efetuadas em dois locais próximo da costa em profundidades de 5 e 9 m, respectivamente, onde os dados foram processados para se obter as análises espectrais e empregado as análises estatísticas do conjunto de amostragem. Nas condiçóes de fronteira, foram considerado os estados de mar estimados $\left(\mathrm{H}_{\mathrm{m} 0}\right.$ - altura de onde significativa, $\mathrm{T}_{\mathrm{p}}$ - período de pico e Dir - direção média em frequência de pico) pelo modelo de escala oceânica, WAVEWATCH III, WWIII. As informações das condiçóes de fronteira foram submetidas a um refinamento para aprimorar a aplicabilidade do modelo, onde se considerou a maré variável para os dois períodos de análise em condiçóes de sizígia, uma vez que a amplitude da maré local chega a ultrapassar os $2 \mathrm{~m}$ durante as fases de sizígia. As informaçốes foram interpoladas de hora a hora para serem introduzidas no conjunto de dados de agitação que forçam o modelo. Os valores numéricos foram obtidos para todo o domínio do cálculo, que considerou como malha exterior as dimensóes da Carta Náutica 720, fornecidas pela Diretoria de Hidrografia e Navegação da Marinha do Brasil. Entretanto, o modelo realizou cálculos em duas malhas de dimensóes inferiores a exterior: uma intermediária e outra interior, esta última na inserção dos pontos de referência, fornecendo assim, os parâmetros de agitação marítima junto à costa. Nos cálculos com o modelo SWAN foram considerados regime estacionário, com a formulação KOMEN e coeficiente de atrito, $c=0.015 \mathrm{~m}^{2} \mathrm{~s}^{-3}$. Analisaram-se também as estatísticas atribuindo o índice de concordância (ic) dos valores medidos e valores numéricos como forma avaliativa. São apresentadas e discutidas as análises comparativas das mediçóes

@ - Corresponding author: fatimalves@geologia.ufrn.br

1 - Universidade Federal do Rio Grande do Norte - UFRN, Programa de Pós-Graduação em Geodinâmica e Geofísica, Departamento de Geologia e Departamento de Engenharia Civil, Campus Universitário Lagoa Nova, C.P: 1596, CEP: 59078-970, Natal, RN, Brasil. e-mail: Matos - fatimaalves@geologia.ufrn.br, Amaro-amaro@geologia.ufrn.br,Scudelari-ada@c.ufrn.br.

2 - Laboratório Nacional de Engenharia Civil-LNEC, Departamento de Hidráulica e Ambiente, Núcleo de Portos e Estruturas Marítimas, Av. do Brasil, 101, 1700-066, Lisboa, Portuga.e-mail: jfortes@lnec.pt 
in situ com as estimativas obtidas com a modelagem numérica, que servem para a validação das simulações, assim como para quantificar as diferenças observadas para ambos os períodos estudados.

Conclui-se que, no geral, o modelo conseguiu representar razoavelmente bem a evolução da onda desde ao largo até a zona de praia. Das análises estatísticas para as alturas significativas, embora se observe semelhança no comportamento, o índice de concordância entre eles, mostrou-se abaixo de 0.5 . Em ambos os casos, em comparaçáo com as observaçóes, houve semelhança no comportamento das alturas significativas e períodos médios, apesar de os valores medidos mostrarem-se sempre superiores aos valores numéricos. No entanto, verificou-se, para a estação do PT1, que o modelo conduz a resultados numéricos mais próximos dos medidos, este em menor profundidade.

A execução deste estudo permitiu realizar os testes quanto a capacidade do modelo SWAN de caracterizar o estado de agitação marítima em zona costeira rasa, com abrangência de escala regional de $300 \mathrm{~km}^{2}$ e obtençáo de resultados satisfatórios.

Palavras-Chave: Modelação numérica, modelo SWAN, ondas, Nordeste do Brasil.

\section{ABSTRACT}

This article presents the comparative analysis of wave propagation between measurements obtained from the results of numerical modeling, with the application of the model SWAN (Booij et al., 1999), and the results of in situ measurements during two campaigns carried out from December 20th through December 27th 2010, and from February 15th through February 22nd 2011, on the northern coast of Rio Grande do Norte, Northeastern Brazil. The SWAN model permits the calculation of the evolution of spectrum from the directional generation zone to the coastline. But like any numerical model is based on approximations and hypotheses, presenting therefore limitations in accurate description of the waves in the area under study. The study's main objective is to evaluate the performance of the SWAN model regarding prediction of sea disturbance, assessing their strengths and limitations for the region of interest.

The in situ measurements were made at two locations near the shore at depths of $5 \mathrm{~m}$ to $9 \mathrm{~m}$, respectively, measured with instruments $A W A C$ and Aquadopp PROFILE, where the data were processed to obtain spectral analysis (significant wave height, HS, period, Tmed, and average direction, DIRmed) and employed the statistical analyzes of all data valid. In the boundary conditions, was considered the estimated sea states ( $H_{m 0}$ - significant wave height, $T_{\text {p }}$-peak period and Dir - direction average peak frequency) by the model of an oceanic scale, provided WWIII (Tolman 1999, 2002). The information of the boundary conditions have been subjected to a refinement to enhance the applicability of the model, where the tide variable considered for two different periods in spring tide conditions, since the amplitude of the local tide comes to exceed $2 \mathrm{~m}$ for phases of spring tide. The data were interpolated hourly to be introduced in the dataset agitation forcing the model. The numerical values were obtained for the entire domain of the calculation, which considered as mesh exterior dimensions of 720 Nautical Chart, provided by the Directorate of Hydrography and Navigation of the Marine of Brazil, however, the model calculations performed in two meshes smaller than outer: one intermediate and one interior, the latter in the insertion of reference points (PT1 and PT2), thereby providing the parameters of wave propagation along the coast. The formulations were considered to SWAN in stationary patterns, formulation KOMEN (1984), with a coefficient of friction $c=0.015 \mathrm{~m}^{2} \mathrm{~s}^{-3}$. We also analyzed the statistics assigning the concordance index (ic) of the measured values and numeric values as a form of evaluation, as well, are presented and discussed comparative analysis of in situ measurements with the estimates obtained with the numerical modeling, which serve to validation of simulations, and to quantify the differences observed for both periods studied.

It is concluded that in general the model represented reasonably well the evolution off from the wave to the beach area. Statistical analyzes to significant heights, although there is similarity in behavior, the level of agreement between the numerical and measured was below 0.5. In both cases, compared with the observations of behavior were similar to significant heights and medium periods, although the measured values show is always higher than the numeric values. However, it is the station PT1 to the model leads to the closest numerical results measured in this shallower depth.

The execution of this study allowed for the tests and the ability of the SWAN model to characterize the state of sea waves in shallow coastal zone, with regional coverage of $300 \mathrm{~km}^{2}$ and satisfactory results.

Keywords: Numeric modeling, wave, Northeastern Brazil.

\section{INTRODUÇÃO}

As zonas costeiras constituem regióes, entre os continentes e os oceanos, caracterizadas pela natureza geológica dos continentes (litologias e arcabouços tectônicos) e principalmente pela energia imposta pela variação do nível médio do mar. No geral, as zonas costeiras mantêmse em condiçôes de equilíbrio dinâmico e, portanto, são áreas muito susceptíveis às mudanças em diversas escalas temporais e espaciais (Suguio, 2003). Grande parte desta dinâmica costeira está direta ou indiretamente relacionada à ação das ondas (Dean \& Darlymple, 2001), correntes, marés e ventos, em intervalos de tempo variáveis. As ondas geradas pelo vento são consideradas o agente forçador dominante na hidro e morfodinâmica costeira (Rocha et al., 2012). Por meio dos fenômenos de refração, difração e reflexão, tendem a amplificar e a transformar a dinâmica na zona costeira por meio da distribuição e dissipação de sua energia ao longo da costa, uma vez que estas respondem, sobretudo, pelo transporte de sedimentos litorâneos e pelos processos erosivos e de deposição (Griggs \& Trenhaile, 1994).

As ondas são o mais importante agente erosivo ao longo da maioria das costas, mas seu efeito varia de acordo com a energia das ondas e características e com a natureza do material exposto a ação das ondas (Summerfield, 1991; Trenhaile \& Kanyaya, 2007). São capazes de colocar em movimento grande quantidade de sedimentos e, consequentemente, modificar a configuração da linha de costa e a distribuição dos sedimentos costeiros no fundo (Davis, 1985), causando o recuo progressivo ou recessão da linha da costa (Griggs \& Trenhaile, 1994).

São vários e evidentes os fatores impactantes relacionados à ação das ondas nas zonas costeira. Muito embora tenha 
havido muitos avanços significativos na compreensão da dinâmica costeira, seu progresso no Brasil tem sido dificultado tanto pelo baixo número de pesquisadores ativos nesta área quanto pelas próprias operacionalidades instrumentais que envolvem a manutenção do monitoramento costeiro, especialmente quanto à temporalidade e distribuição espacial de locais permanente para o monitoramento das ondas, sobretudo, no litoral do nordeste do Brasil, que abrange uma área de $3.036 \mathrm{~km}$ de extensão, representando mais de $1 / 3$ do litoral brasileiro, onde existe uma ausência de locais fixos de monitoramento a médio e longo prazo. Apesar disso, alguns estudos (Tabosa et al., 2002; Silveira, 2002; Lima, 2002; 2006; Chaves, 2005; Leite, 2007; Scudelari et al., 2007; Góes, 2009; Scudelari et al., 2011; Matos et al., 2011; Fortes et al., 2011; Matos \& Amaro, 2011; Ferreira et al., 2012) têm sido feitos e vale ressaltar sua importância para os programas de monitoramento ambiental do litoral norte do Rio Grande.

Desta maneira, no que se refere ao ambiente marinho e costeiro, modelos de propagação de ondas são imprescindíveis para o conhecimento e o entendimento do ambiente estudado. A maioria dos modelos matemáticos sugere que as ondas exercem as maiores pressóes na, ou ligeiramente acima, superfície média da água (Trenhaile, 2002). Uma das formas mais evidentes para se determinar o clima de ondas é por meio da medição in situ propriamente dita. Entretanto, devido à própria complexidade dos sistemas costeiros (Trenhaile, 2002), e pelas dificuldades instrumentais e custos envolvidos (Marques, 1997), diversos países há várias décadas têm desenvolvido e utilizado modelos numéricos para previsão de ondas, tanto em escala regional como global. Assim como no passado, estes modelos se encontram em constante fase de aperfeiçoamento para melhorar o desempenho das previsóes numéricas da agitaçáo marítima, bem como de se obter uma caracterização de maior cobertura geográfica e com maior capacidade de prever um estado de agitação marítima das áreas de interesse.

Um dos mais utilizados modelos na previsão da agitação marítima é o modelo SWAN (Booij et al., 1999), que permite o cálculo da evolução do espectro direcional desde a zona de geração até à zona costeira. Mas, como qualquer modelo numérico, é baseado em aproximações e hipóteses, apresentando por isso, limitaçóes na descrição precisa das ondas na zona em estudo. Além disso, este tipo de modelos envolve um conjunto de parâmetros que têm de ser calibrados para cada caso de estudo, recorrendo, por exemplo, a dados adquiridos in situ. Uma das grandes vantagens do modelo SWAN é a versatilidade, já que pode ser aplicado a grandes zonas costeiras abertas ou pode ser aplicado a zonas confinadas, como baías e estuários, por exemplo.

Desta forma, a existência de mediçôes in situ (sobretudo, de ondas) no Litoral Setentrional do Rio Grande do Norte é uma oportunidade de calibrar alguns parâmetros do modelo numérico SWAN bem como de avaliar o desempenho do modelo e justificam o interesse do presente trabalho.

A modelação numérica com o SWAN foi efetuada para os dias em que foram realizadas as campanhas de mediçôes in situ, i.e., 20 a 27 de Dezembro de 2010 e 15 a 22 de Fevereiro de 2011.
Embora para esta região a aplicação do SWAN já tenha sido efetuada anteriormente por outros autores (Scudelari et al., 2007; Scudelari et al., 2011; Fortes et al., 2011; Ângelo, 2012), neste estudo a proposta é refinar a inserção dos dados e aprimorar a condição aplicável do modelo., Considerou-se a maré variável para um conjunto significativo de dias sob a influência das marés de sizígias, uma vez que estas, por serem meso marés semidiurnas, influenciam e contribuem em escala diária no retrabalhamento, mobilização e transporte dos sedimentos junto à costa.

Assim, com base nos resultados do modelo de previsão da agitação marítima, WAVEWATCH III, Tolman (1999; 2002), da bóia localizada na costa norte do Nordeste do Brasil (nas coordenadas 787460,84E / 9666781,81S), para os dias de mediçóes in situ, utilizando dados de altura significativa $(H S)$, período médio (Tmed) e direção média (DIRmed), medidos com os instrumentos AWAC e AQUADOPP PROFILE, foram efetuados os cálculos com o modelo SWAN desde o largo (230 km de distância da costa) até a zona de próxima da costa, onde se obteve os valores de altura de onda significativa, H_S, período médio, T_med e direção média, DIR_med, na zona de estudo. Foi realizada uma análise comparativa das mediçóes da agitação marítima local com as estimativas produzidas pelo modelo em dois pontos localizados próximos da costa e calcularam-se as estatísticas.

Neste sentido, este trabalho descreve os procedimentos de preparação e de aquisição de dados durante as campanhas de campo; os procedimentos de tratamento e análise dos dados; a aplicação do modelo SWAN; as análises comparativas e a avaliação do desempenho do modelo SWAN nesta zona de estudo com base nos dados medidos.

\subsection{Características Gerais da Área de Estudo}

O Litoral Setentrional do Rio Grande do Norte está situado na região nordeste do Brasil, no contexto das regióes semiáridas, com baixa precipitação anual (<750 mm/ano) e altas temperaturas $\left(>25^{\circ} \mathrm{C}\right)$, caracterizando-se assim, como uma região altamente vulnerável às condiçóes impostas pela variação do nível do mar e pelas mudanças climáticas.

$\hat{E}^{\prime}$ uma costa de plataforma continental rasa, inserida no contexto geológico da Bacia Potiguar, onde da linha de costa em direção ao talude, às profundidades variam aproximadamente de $10 \mathrm{~m}$ até $40 \mathrm{~m}$, a partir daí, ocorre gradualmente o desnível superior a $2.000 \mathrm{~m}$ sobre o talude e o sopé continental (Gomes, 2009). A porção interna da plataforma continental é constituída por um sistema de ilhas barreiras e esporôes arenosos extremamente susceptíveis aos processos erosionais, intensamente afetado pelas condiçóes hidrodinâmica, eólicas, e pelo arranjo estrutural de um sistema de falhamentos reativados no tempo (Fonseca, 1996; Caldas, 2002; Souto et al., 2006; Rios et al., 2012). O sistema de falhas Carnaubais (NE-SW) e de Afonso Bezerra (NW-SE) corresponde à principal estrutura que controla a sedimentação na bacia, assim como, a deposiçáo dos sedimentos costeiros.

Na zona próxima a linha de costa (Figura 1), a instabilidade morfológica é intensa, com forte atuação dos processos de erosão e de acreção, resultantes da ação constante das ondas, das variaçóes do nível médio da água do mar, das condiçóes 
climáticas, das sequências geológicas, das atividades neotectônicas e do suprimento de sedimentos carreados pelos rios e oceano, que controlam o desenvolvimento de feições erosivas e construtivas na faixa litorânea (Souto et al., 2006).

Além destes aspectos atuantes na modificação da morfologia costeira, tem destaque a interferência antrópica, fortemente ocupada por empreendimentos de grande porte (Figura 1a, 1b), como as atividades petrolíferas instaladas em águas rasas e zona de intermaré, que envolve desde a prospecçáo, a exploração e transporte de petróleo e gás natural, e mantém a área, que apresenta uma vulnerabilidade ambiental e natural elevadas (Grigio et al., 2005, Boori \& Amaro, 2010), em constante risco ambiental.

Ressalta assim, a importância de conhecer os padróes de propagação das ondas na região de intensa dinâmica costeira, para entender os efeitos desta sobre a morfodinâmica costeira.

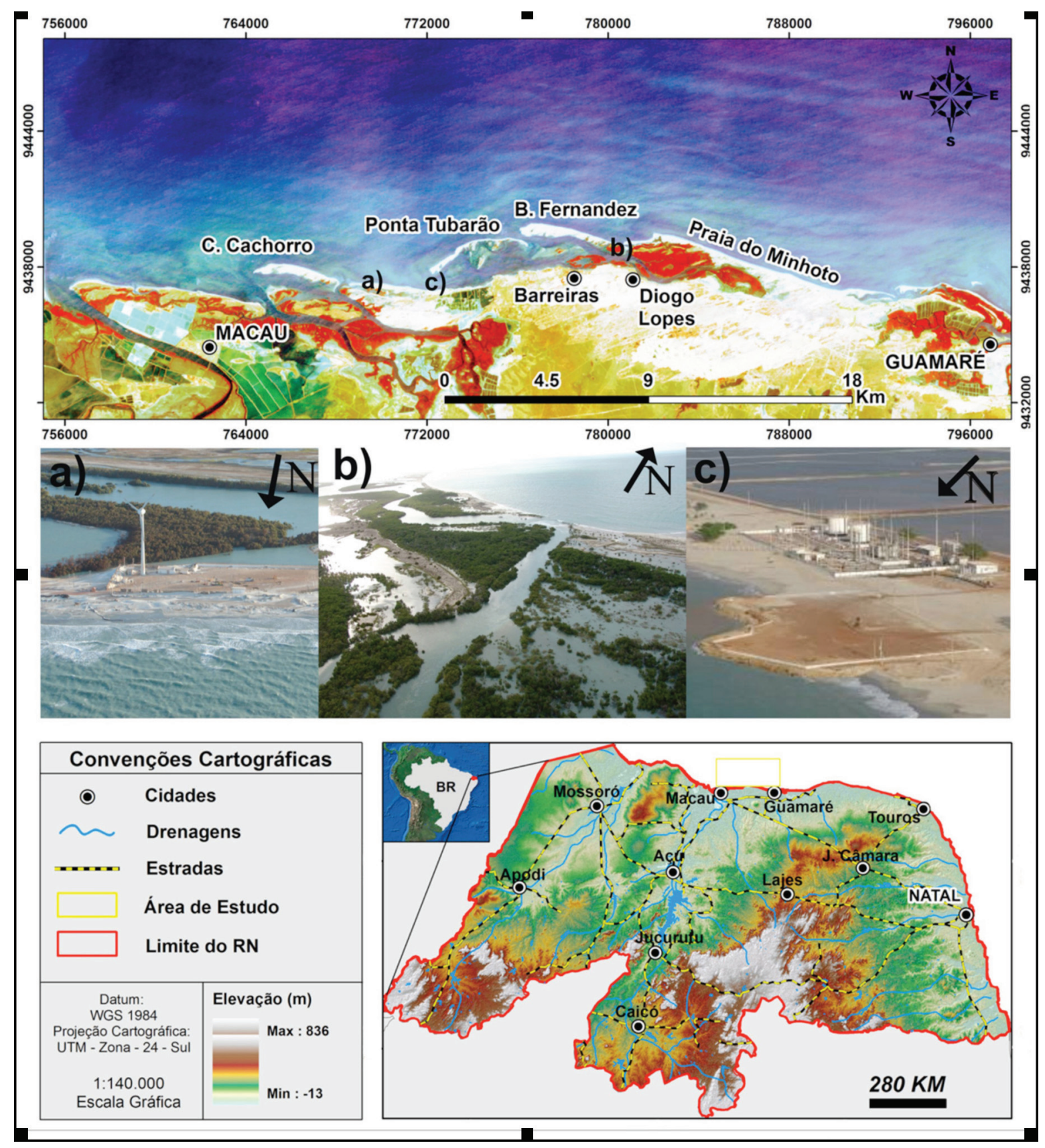

Figura 1. Mapa de localização da área de estudo. Atividades de uso e ocupação: a) instalaçóes de aerogeradores; b) sistema de manguezais; c) indústria do petróleo.

Figure 1. Location of the study area. Activies use and occupation: wind turbines installations; b) mangrove; c) oil industry. 


\section{MEDIÇÓES IN SITU E TRATAMENTO DOS DADOS}

As características das duas campanhas de mediçóes de ondas consideradas neste trabalho efetuadas na zona marítima próxima da ilha do Tubarão são descritas sucintamente na tabela 1 onde, a posição geográfica é referenciada ao Datum WGS-1984, zona 24 Sul, em sistemas de coordenadas UTM. Em Matos et al. (2011) descrevem-se com maior pormenor essas campanhas. Os instrumentos de medição utilizado nas campanhas foram: o AWAC - Acustic Wave and Current Meter, que mede os parâmetros de ondas (altura significativa e altura máxima, período de pico e período médio, direção de pico e direção média, pressão) e o AQUADOPP PROFILER, que mede os parâmetros de ondas e correntes (velocidade da corrente, direção da corrente, temperatura, pressão, altura da onda, período médio e de pico, direção média e direção de pico, entre outros parâmetros), ambos os instrumentos do mesmo fabricante, NORTEK AS, e que medem com frequência de aquisição de $1 \mathrm{~Hz}$, respectivamente, (Figura 2).

Os dados foram processados pelo software Storm do mesmo fabricante, NORTEK AS, para obter os parâmetros da onda (altura significativa, altura máxima, período de pico, período médio, direçâo de pico e direção média). O software utiliza como método e algoritmo padrão para o processamento, foi o MLMST (Método Máxima Verossimilhança com Rastreamento de Superficie). Este método é o mais indicado para o processamento de série de mediçóes de onda com AWAC AST (Kahma et al., 2005; Pedersen et al., 2007). Por este método, é obtido um significativo conjunto de estimativas de onda:

- Estimativa da altura da onda significativa $(\mathrm{Hm} 0)$;

- Período de médio (TM02) baseado nos momentos de espectros de energia;

- Direção média (MeanDir) que corresponde a direção de energia ou à direção média. A ponderaçáo de energia é aplicada aos coeficientes de Fourier.

Outro tipo de dados considerado no presente trabalho referem-se às características dos ventos medidos e obtidos pela estação Meteorológica de Macau e às condiçóes de maré medidas e obtidas pela estação Maregráfica de Macau, $\mathrm{X}=7753257 \mathrm{E} / \mathrm{Y}=9434173 \mathrm{~N}$ (Datum WGS1984, Zona 24 Sul, UTM).

$\mathrm{Na}$ Figura 3 e Figura 4, apresentam-se os dados de ventos (velocidade e direção) para os dois períodos distintos das mediçóes in situ: 20 a 27 de Dezembro de 2010 e 15 a 22 de Fevereiro de 2011. Nota- se que durante o período de 20 a 27 de dezembro de 2010 (PT2) e 15 a 22 de fevereiro de 2012 (PT1), a velocidade média dos ventos foi de $5,49 \pm 3,83 \mathrm{~m} / \mathrm{s}$, com direçôes variando entre NE, E e SE, principalmente. A Figura 3 e 4 ilustra as condiçóes dos ventos, destacando os dois períodos relacionados às campanhas de mediçóes in situ.

Tabela 1. Descrição das campanhas de aquisição dos dados.

Table 1. Main characteristics of the data acquisition campaigns.

\begin{tabular}{lllll}
\hline Mediçóes & Data & Sensor & Prof $(\mathbf{m})$ & Localizaçáo \\
\hline PT1 & 15 a 22/02/11 & AQUADOPP & 5 & $X=766768, Y=9441999$ \\
\hline PT2 & 20 a 27/12/10 & AWAC & 8 & $X=779765, Y=9447091$ \\
\hline
\end{tabular}

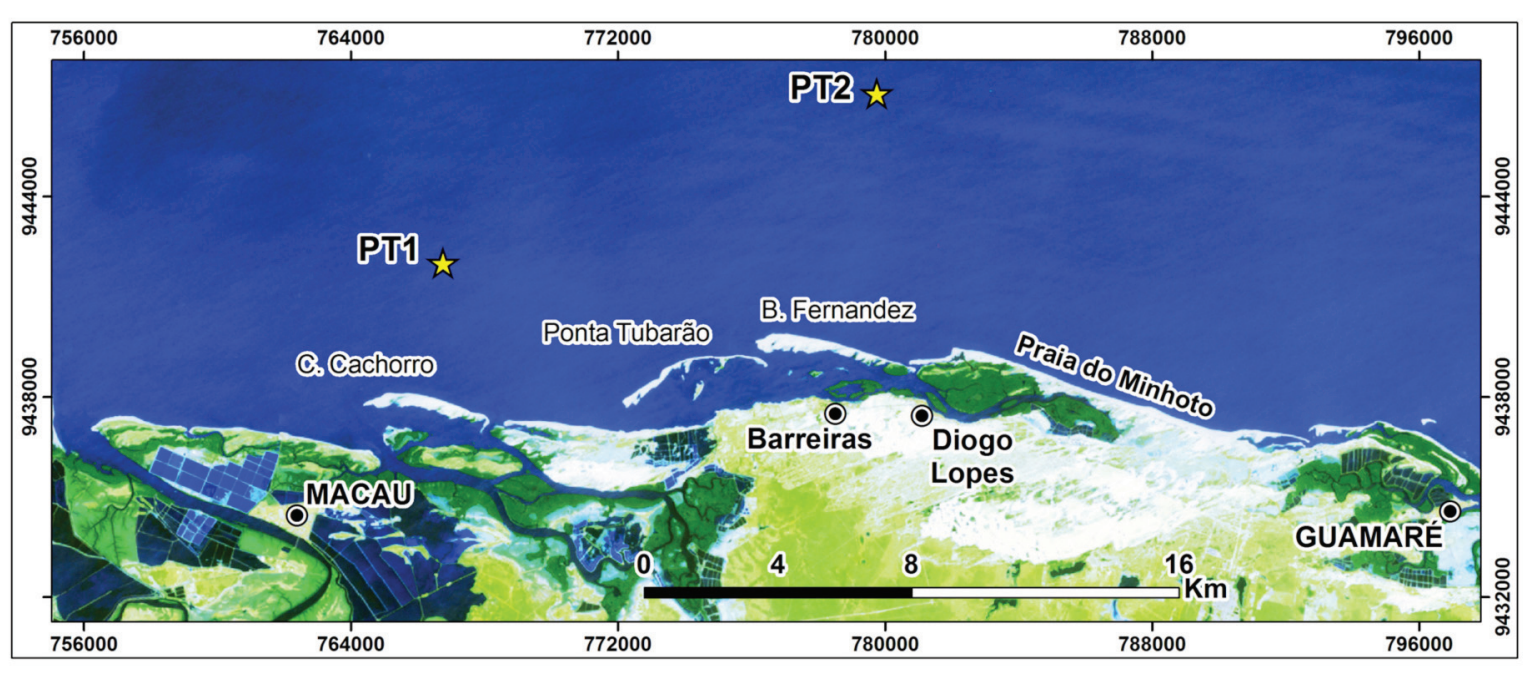

Figura 2. Mapa de localização do posicionamento dos sensores para as campanhas PT1 e PT2.

Figure 2. Map location of the sensor ( PT1 and PT2) during the campaigns. 


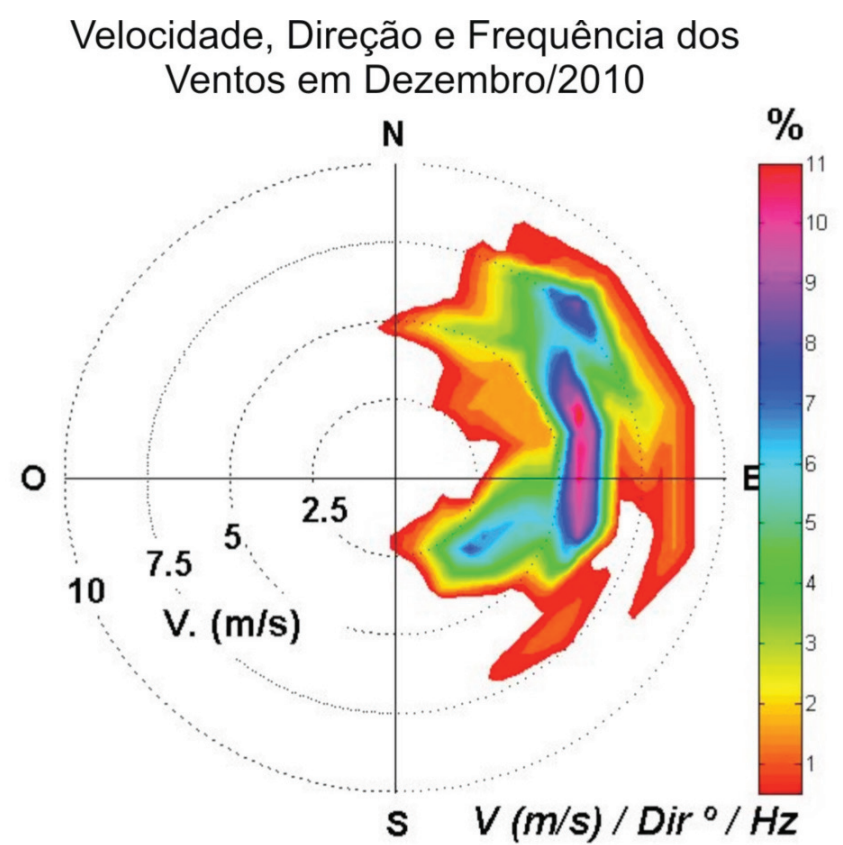

Figura 3. Características dos ventos, velocidade $(\mathrm{m} / \mathrm{s})$, e direção Dir (o) de 20 a 27 de Dezembro de 2010.

Figure 3. Wind characteristics (vel $(\mathrm{m} / \mathrm{s})$, Dir $\left.\left({ }^{\circ}\right)\right)$ on 20 to 27 December, 2010.

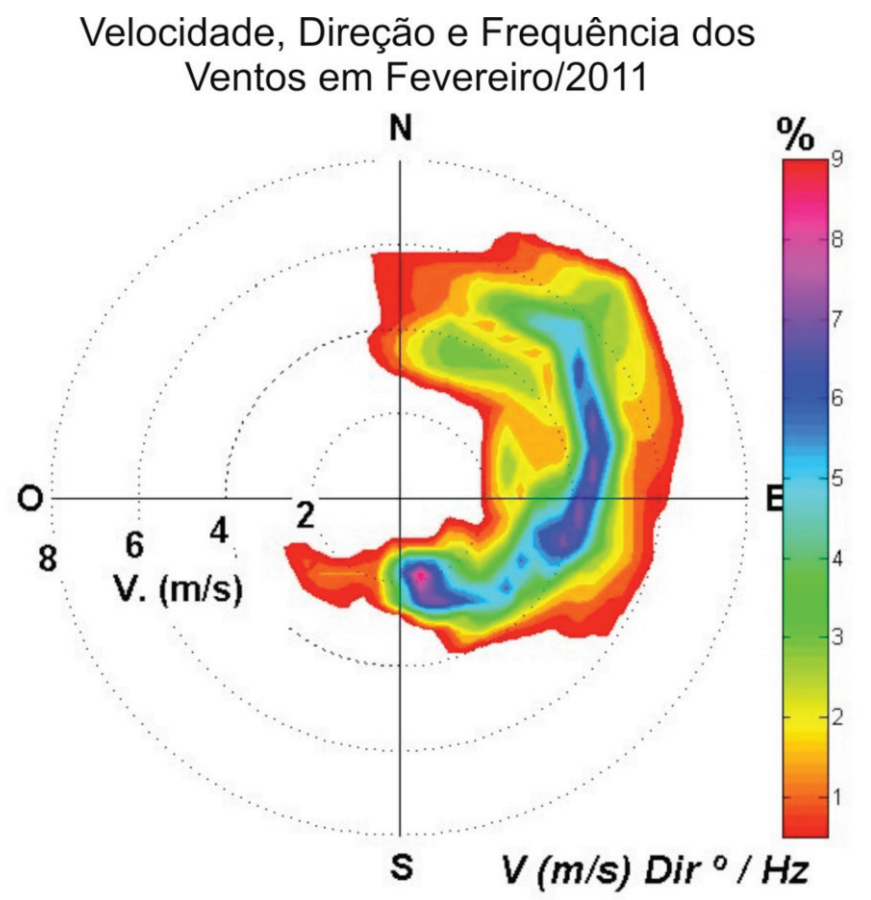

Figura 4. Características dos ventos, velocidade $(\mathrm{m} / \mathrm{s})$ e direção $(\mathrm{o})$ de 15 a 22 de Fevereiro de 2011.

Figure 4. Wind characteristics (vel (m/s), Dir (o)) on 15 to 22 February, 2011.
$\mathrm{Na}$ figura 5 apresentam-se os valores da maré, obtidos para o período de 20 a 27 de Dezembro de 2010 a 15 a 22 de Fevereiro de 2011, da estação maregráfica de Guamaré, $\mathrm{X}=797490 \mathrm{E} / \mathrm{Y}=9435570 \mathrm{~N}$ (Datum WGS1984, zona 24 Sul). A maré local é semi-diurna, onde o nível médio $\left(\mathrm{Z}_{0}\right)$ estabelecido é $139 \mathrm{~cm}$ acima do RN (Nível de Redução) com médias de preamares de sizígia (MHWS) de $234 \mathrm{~cm}$ acima do $\mathrm{RN}$, média de preamares de quadratura de (MHWN) de $221 \mathrm{~cm}$, média de baixa-mares de sizígia (MLWS) de 43 $\mathrm{cm}$ abaixo do $\mathrm{RN}$ e média das baixa-mares de quadratura (MLWN) de $56 \mathrm{~cm}$.
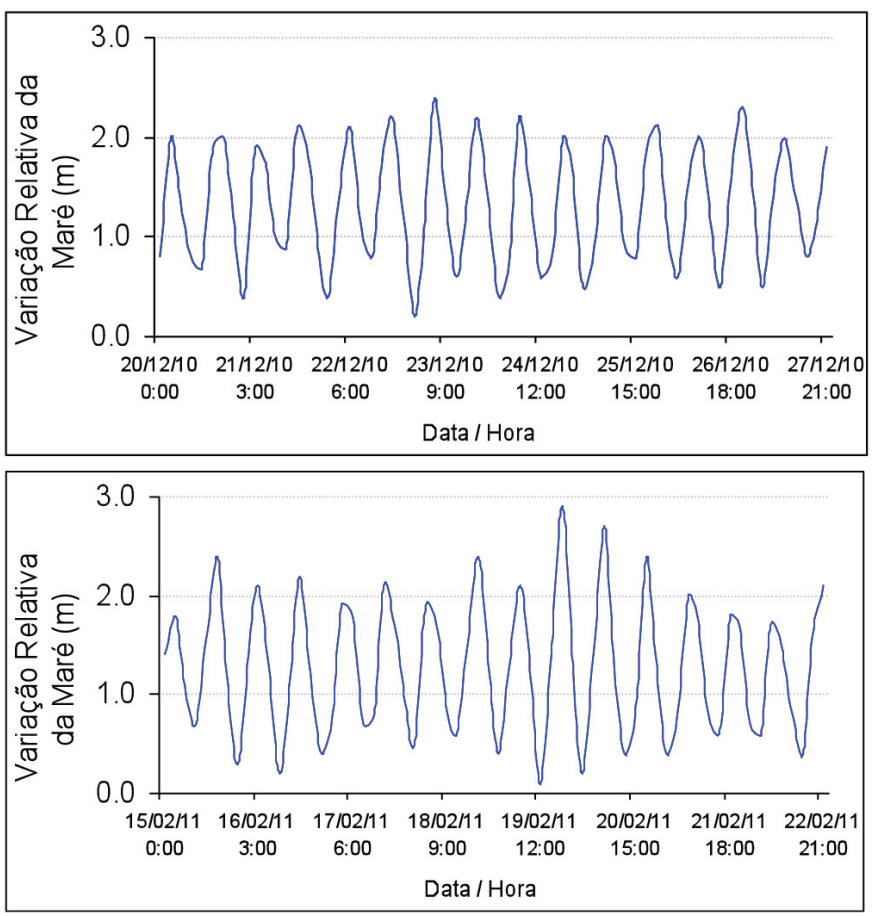

Figura 5. Características da variação da maré local para os dias 20 a 27 de Dezembro de 2010 e 15 a 22 de Fevereiro de 2011.

Figure 5. Tidal variation on 20 to 27 December 2010 and on 15 to 22 February 2011.

\subsection{Análise dos Dados Válidos de Ondas}

Com os dados obtidos pelo AWAC (PT2) e AQUADOP (PT1), foram executadas análises temporal e espectral dos registros, que permitiram obter um conjunto de parâmetros estatísticos da onda, de uma amostragem de 357 aquisiçóes no PT1 e 384 aquisições no PT2. Na Figura 6 e Figura 7 são apresentadas os resultados das análises espectrais efetuadas aos registros obtidos em cada localizaçáo do equipamento (PT1 e PT2) respectivamente, no que se refere aos valores da altura de onda significativa HS (ou HM0), altura máxima (HMAX), período médio Tmed (ou TM02), período de pico (TP), direção média DIRmed e direção de pico DIR_TP ao longo do período das campanhas.

Verifica-se que para o PT1, as alturas de onda significativas e alturas máximas crescem significativamente em dois períodos ao longo de todos os dias de mediçóes, nas primeiras horas do dia e posteriormente no período da tarde, sendo 
que período as ondas alcançam as maiores alturas, tanto nas significativas quanto nas alturas máximas, $1.25 \mathrm{~m}$ e $2.09 \mathrm{~m}$ respectivamente. No PT2, a altura da onda significativa e altura máxima crescem ao longo do dia, de forma semelhante as do PT1. Entretanto, na medida em que decorrem os dias seguintes, as alturas significativas e alturas máximas tendem a maior ascensão nos períodos da tarde, com alturas de 2.04 $\mathrm{m}$ e $3.41 \mathrm{~m}$, respectivamente. As similaridades nas alturas significativas e alturas máximas do PT1 e PT2 sugere que sâo ondas regulares tipicamente geradas por ventos e sob a influência das marés semidiurnas, uma vez que as maiores alturas das ondas assemelham-se aos horários da maré de enchente.

Quanto aos períodos médios e períodos de pico, as ondas de maiores períodos se propagam entre o intervalo de $05 \mathrm{~h} 00$ e 08h00, com médias máximas de $6.67 \mathrm{~s}$ e $7.84 \mathrm{~s}$, sendo as mais frequentes as ondas com períodos médios entre 4.3 $s$ e 5.5 s no PT1. Para PT2, os maiores períodos médios variam em horários de $05 \mathrm{~h} 00$ e $10 \mathrm{~h} 00$, com valores entre 6.9 s e $8.1 \mathrm{~s}$, entretanto, os períodos médios mais frequentes são $3.3 \mathrm{~s}$ e $4.5 \mathrm{~s}$. Tais valores indicam que as ondas são predominantemente geradas por ventos locais.

Nos valores médios direcionais do PT1, as ondas mais frequentes são as de direções entre $179^{\circ}$ a $269^{\circ}$, predominantemente de SW, seguidas das direçóes NW, com valores entre $269^{\circ}$ a $359^{\circ}$. No PT2, 78\% das direçóes médias variaram entre $0.15^{\circ}$ a $90^{\circ}$, caracterizando as ondas neste ponto predominantemente de NE.

Na tabela 2 e 3, mostram-se as características das estatísticas (valores máximo, médio e mínimo, erro e desvio padrão e dimensóes da amostragem) nos dois períodos de amostragem (20 a 27 de Dezembro de 2010 e de 15 a 22 de Fevereiro de 2011) para os locais PT1 e PT2, respectivamente.

\section{SIMULAÇÓES NUMÉRICAS}

Para a aplicação efetuada com o modelo SWAN na zona em estudo com vista a caracterizar a agitação marítima para os períodos das campanhas, o procedimento seguido foi:

- Utilização como condiçóes ao largo do SWAN as fornecidas pelo modelo de geração de onda, WAVEWATCH III, WWIII (Tolman, 1999, 2002) para bóia localizada na costa norte do Nordeste do Brasil, distante cerca de $230 \mathrm{~km}$ da costa;

- Utilização dos dados dos ventos e dos dados de marés para os dois períodos distintos, de 20 a 27 de Dezembro de 2010 e 15 a 22 de Fevereiro de 2011;

- Cálculo das características das ondas (HS, Tmed e DIRmed) em locais diferentes, posicionados na zona marítima adjacente a ilha do Tubarão, na porção setentrional do Rio Grande do Norte, utilizando o modelo SWAN para os períodos referidos;

- Comparação dos valores numéricos das alturas de onda significativas, períodos médios e direçóes médias com as mediçóes efetuadas nos pontos PT1 e PT2.

\subsection{O Modelo SWAN}

O modelo SWAN (Booij et al., 1999) acrónimo de Simulating WAves Nearshore é um modelo numérico para
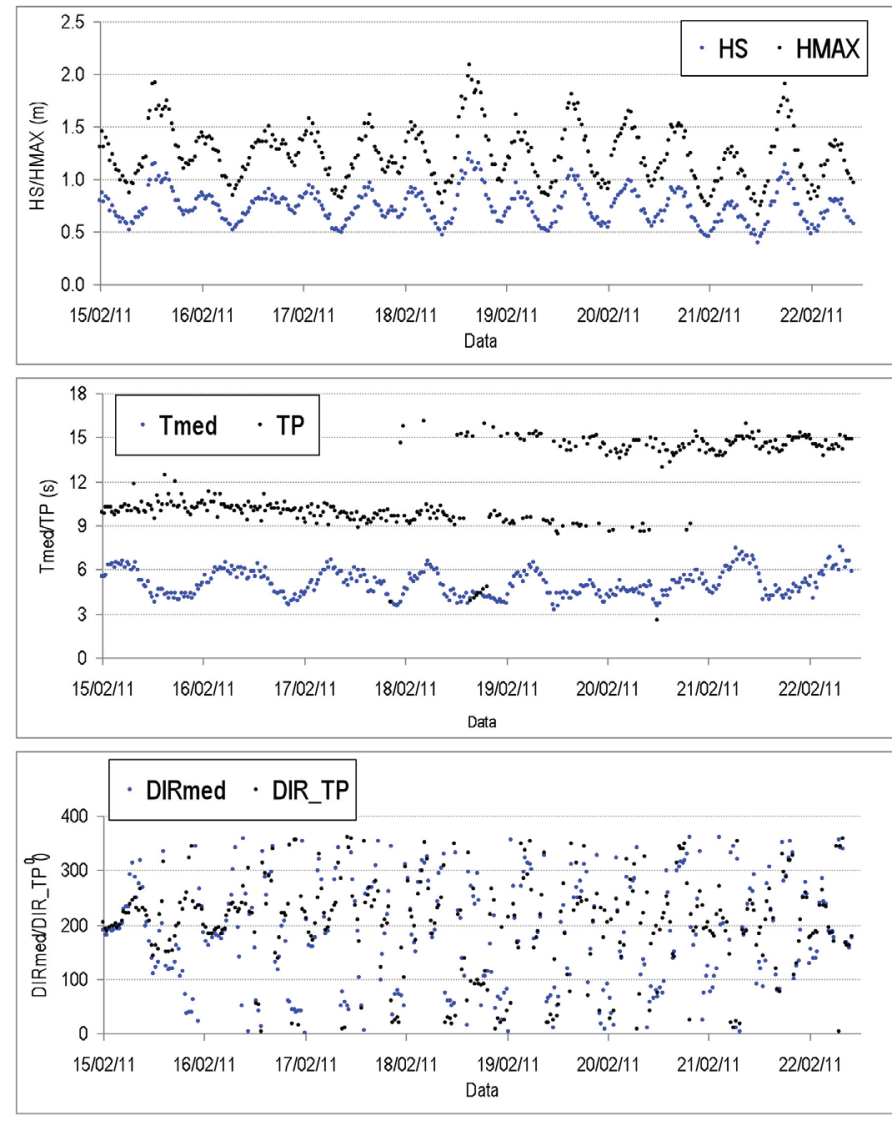

Figura 6. Características da agitação marítima medida nos períodos de 20 a 27 de Dezembro de 2010 e 15 a 22 de Fevereiro de 2011 para os instrumentos localizados em PT1, altura de onda significativa, HS (m), altura máxima $\operatorname{Hmax}(\mathrm{m})$, período médio, Tmed (s), período de pico TP (s), direção média, DIRmed (o) e direção de pico DIR_TP $(\mathrm{o})$.

Figure 6. Wave characteristics for PT1 instrument, significant wave height, HS (m), maximum wave height $H \max (m)$, mean wave period, Tmed (s), peak period TP (s), mean wave direction, DIRmed (o) and peak direction TpDir (o), for different periods: 15 a 22 February, 2011.

geração, propagação e dissipação da agitação marítima, baseado na equação para a conservaçáo da açáo de onda. Trata-se de um modelo de domínio público (freeware), em constante desenvolvimento pela Delft University of Technology da Holanda, que possui como uma das maiores vantagens a manutenção da estrutura dos ficheiros de dados e de resultados o que permite a fácil atualização de versóes mais robustas e completas do modelo sempre que necessário.

Este modelo propaga a agitação marítima desde o largo até próximo da costa considerando os processos físicos de refração, difração e empolamento devido a variações do fundo e presença de correntes, crescimento de onda por ação dos ventos, rebentação por influência do fundo e por excesso de declividade (whitecapping), dissipação de energia devido à fricção do fundo, bloqueio e reflexão por correntes opostas e transmissão através de obstáculos.

O campo de ondas na zona em estudo é caracterizado pelo espectro bidimensional de densidade da ação da agitação 

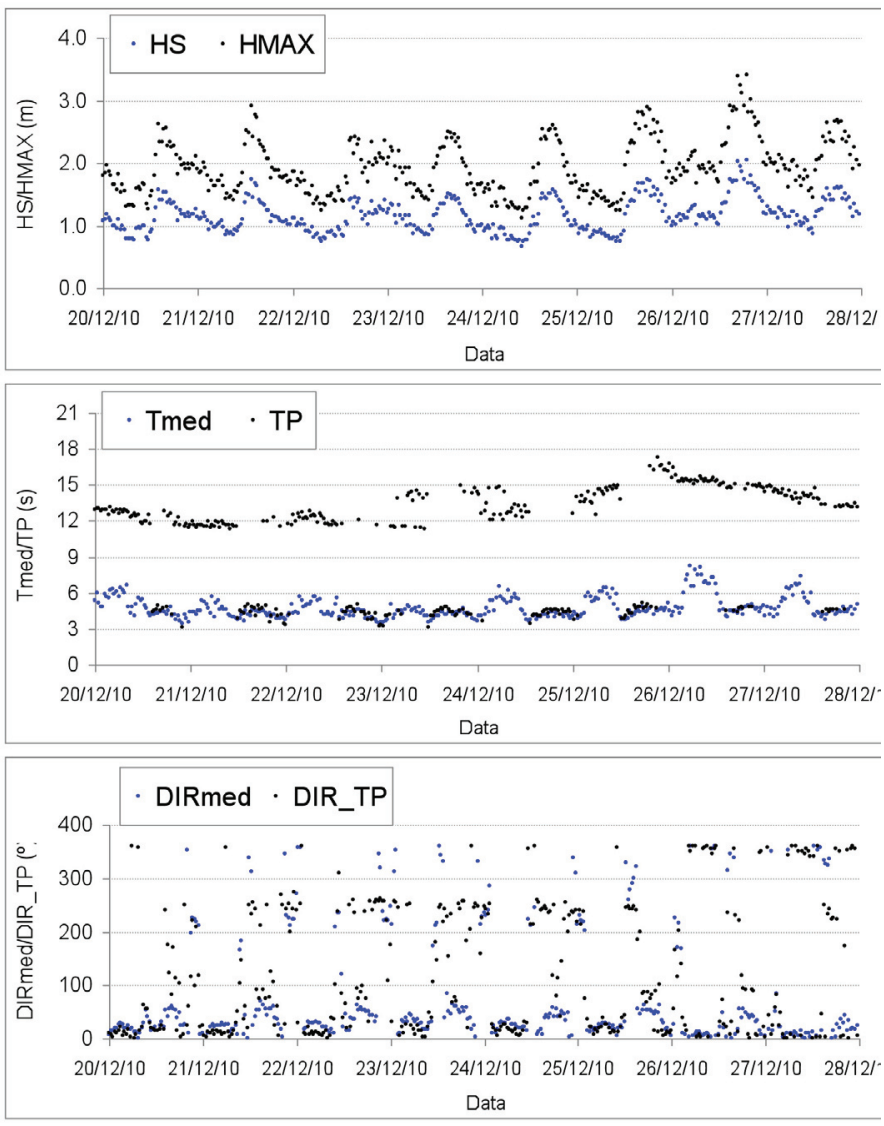

Figura 7. Características da agitação marítima medida nos períodos de 20 a 27 de Dezembro de 2010 e 15 a 22 de Fevereiro de 2011 para os instrumentos localizados em PT2, altura de onda significativa, HS $(\mathrm{m})$, altura máxima $\mathrm{Hmax}(\mathrm{m})$ período médio, Tmed (s), período de pico TP (s), direção média, DIRmed (o) e direção de pico DIR_TP (o).

Figure 7. Wave characteristics for PT2 instrument, significant wave height, HS (m), maximum wave height $H \max (m)$, mean wave period, Tmed (s), peak period TP (s), mean wave direction, DIRmed ( ${ }^{\circ}$ and peak direction TpDir ( $)$, for different periods: 20 to 27 December 2010. marítima. Com esta representação, é possível a aplicação do modelo em áreas onde o crescimento da agitação marítima pela ação do vento seja notável ou onde estado de mar, ou mesmo ondulação esteja presente. A propagação da agitação, nos modos estacionário, nos espaços geográfico e espectral, é realizada utilizando esquemas numéricos implícitos. A zona em estudo pode ser descrita com coordenadas cartesianas ou esféricas, utilizando uma malha "retangular".

Os dados necessários para a execução do SWAN são a malha batimétrica da zona a modelar e as condiçóes de agitação na fronteira de entrada do domínio, para além de um conjunto de outros parâmetros de cálculo. De entre os vários resultados obtidos pelo SWAN destacam-se a altura de onda significativa, os períodos de pico e médio, as direçóes de pico e média, a dispersão direcional, o parâmetro de largura de banda e o nível de água em qualquer parte do domínio computacional.

Para a preparação dos dados, execução e visualização dos resultados do modelo SWAN, foi usado a ferramenta SOPRO (Fortes et al., 2007), desenvolvido pelo Laboratório Nacional de Engenharia Civil de Portugal.

\subsection{Condiçóes de aplicação}

\subsubsection{Batimetria, Condiçóes Fronteira ao Largo, Ventos e Marés}

A execução do modelo SWAN requer a introdução de diferentes dados de base, referentes às variáveis físicas que caracterizam o local e as condiçóes ambientais tais como a batimetria, agitação ao largo, ventos e marés.

A batimetria empregue no modelo SWAN (Figura 8) foi obtida das informaçóes da carta náutica 720 , fornecidas pela Diretoria de Hidrografia e Navegação - DHN da Marinha do Brasil, com 25.077 pontos batimétricos digitalizados.

Consideraram-se como condiçóes ao largo os estados de mar estimados pelo modelo de escala oceânica, de $3^{\text {a }}$ geraçáo e propagação de ondas WAVEWATCH, WWIII (Tolman, 2002). Estas estimativas são definidas por: $\mathrm{H}_{\mathrm{m} 0}$ (altura de

Tabela 2. Estatística descritiva para os parâmetros descritores da agitação do PT1.

Table 2. Descriptive statistics for wave heights, PT1.

\begin{tabular}{lllllll}
\hline Parâmetros & HS $(\mathbf{m})$ & HMAX $(\mathbf{m})$ & TP $(\mathbf{s})$ & Tmed $(\mathbf{s})$ & DIR_TP $(\mathbf{o})$ & DIRmed (o) \\
\hline Máximo & 1.25 & 2.09 & 16.08 & 7.48 & 358.77 & 359.24 \\
\hline Média & 0.74 & 1.23 & 11.63 & 5.06 & 199.51 & 185.64 \\
\hline Mínimo & 0.39 & 0.66 & 2.57 & 3.19 & 2.39 & 0.17 \\
\hline Erro Padrão & 0.01 & 0.01 & 0.14 & 0.25 & 4.60 & 5.18 \\
\hline Desvio Padrão & 0.16 & 0.27 & 2.68 & 0.89 & 86.89 & 97.81 \\
\hline Amostragem & 357 & 357 & 357 & 357 & 357 & 357 \\
\hline
\end{tabular}


Tabela 3. Estatística descritiva para os parâmetros descritores da agitação do PT2.

Table 3. Descriptive statistics for wave heights, PT2.

\begin{tabular}{lllllll}
\hline Parâmetros & HS $(\mathbf{m})$ & HMAX $(\mathbf{m})$ & TP $(\boldsymbol{s})$ & Tmed $(\mathbf{s})$ & DIR_TP $(\mathbf{o})$ & DIRmed $(\mathbf{o})$ \\
\hline Máximo & 2.04 & 3.41 & 17.30 & 8.18 & 359.93 & 359.93 \\
\hline Média & 1.15 & 1.93 & 10.31 & 4.70 & 123.31 & 80.66 \\
\hline Mínimo & 0.67 & 1.12 & 3.06 & 3.37 & 0.11 & 0.15 \\
\hline Erro Padrão & 0.01 & 0.02 & 0.23 & 0.04 & 6.21 & 5.43 \\
\hline Desvio Padrão & 0.26 & 0.44 & 4.45 & 0.88 & 121.73 & 106.47 \\
\hline Amostragem & 384 & 384 & 384 & 384 & 384 & 384 \\
\hline
\end{tabular}

onda significativa), $\mathrm{T}_{\mathrm{p}}$ (período de pico) e Dir (direçáo média para a frequência de pico), obtidas a cada três horas, referentes ao período de 20 de 27 de Dezembro de 2010 e de 15 a 22 de Fevereiro de 2011, para o ponto da malha $\mathrm{X}=753257 \mathrm{E} / \mathrm{Y}=9668067 \mathrm{~N}$, selecionado por estar localizado o mais próximo da área de estudo (Figura 8).

A partir destes valores integrais, $\mathrm{H}_{\mathrm{m} 0}$ e $\mathrm{T}_{\mathrm{p}}$ parametrizouse um espectro JONSWAP com $\gamma=3.3$ para representar a dependência em frequência. A distribuição em direção é dada por uma potência da função cosseno com expoente 10 .

\subsubsection{Dominio Computacional e condiçóes gerais}

A necessidade de utilização de mais que uma malha de cálculo está relacionada com a expectativa de melhor desempenho do modelo numérico face à utilização de apenas uma, quer no que se refere à qualidade da previsão, quer ao tempo necessário ao cálculo.

As características da agitaçáo ao largo, constituem a condiçáo de fronteira na malha global - Externa, em um ou dois dos lados dessa fronteira, dependendo da direcção daquela agitação. Os resultados da malha global fornecem as condiçôes de fronteira para a $2^{\mathrm{a}}$ malha - Intermediária, $\mathrm{e}$ os resultados desta malha fornecem as condiçóes de fronteira para a $3^{\text {a }}$ malha -Interna (Figura 8).

Para os cálculos com o modelo SWAN, utilizaram-se três malhas encaixadas (Figura 8).

Para a execução dos cálculos do modelo foram utilizadas as seguintes condiçôes:

- Uso da versão SWAN 40.72, em modo estacionário sem correntes;
- Consideraçáo dos dados de ventos fornecidos pela estaçáo meteorológica de Macau, admitindo constância dos valores de velocidades e de direçôes em todo o domínio;

- Utilização dos dados da variação da maré local, fornecidas pela estação maregráfica de Macau;

- Uso de um coeficiente de rebentação constante de 0,65 para os períodos distintos;

- Uso de um espectro direcional discretizado em 21 intervalos, de 0,04 a $1.0 \mathrm{~Hz}$, com distribuiçáo logarítimica e discretização em direção que cobre $360^{\circ}$, dividida em 180 intervalos $\left(\Delta=10^{\circ}\right)$;

- Uso da Lei de JONSWAP (Hasselmann et al., 1973);

- Parâmetro de atrito de fundo o valor de $0.015 \mathrm{~m}^{2} \mathrm{~s}^{-3}$ (Komen, et al., 1984), em regime estacionário.

Os fenómenos físicos incluídos foram:

$\mathrm{Na} 1^{\text {a }}$ malha externa: a refracção, o empolamento e a rebentação por influência do fundo e do excesso de declividade (whitecapping), a difracção e interacçóes onda-onda quadruplets (quadruplet wave-wave interactions);

Nas $2^{a}$ e $3^{a}$ intermediária e interna: a refracção, o empolamento e a rebentaçáo por influência do fundo e do excesso de declividade (whitecapping), as interacçóes entre tríades de ondas (triad wave-wave interactions), a geração de harmónicas (frequency shifting) e a difracção.

\begin{tabular}{lcccc}
\hline Domínios & X inicial & Y inicial & Dimensóes $(\mathbf{k m})$ & Resoluçáo $(\mathbf{x}, \mathbf{y})$ \\
\hline $1^{\mathrm{a}}$ Externa & 710000 & 9436000 & $100 \times 62$ & $(1000,1000)$ \\
\hline $2^{\mathrm{a}}$ Intermediária & 750000 & 9440000 & $50 \times 20$ & $(500,250)$ \\
\hline $3^{\mathrm{a}}$ Interna & 765000 & 9440000 & $30 \times 10$ & $(100,50)$ \\
\hline
\end{tabular}

Figura 8. Malhas batimétricas utilizadas no domínio computacional.

Figure 8. Bathymetric grids used in the computational domain. 


\subsection{Resultados das Características da Agitação Marítima no Domínio do Cálculo}

Na Figura 9 e na Figura 10, apresentam-se os resultados relativos à propagação efetuada com o SWAN, na malha 2 , para o estado de agitaçáo incidente verificado nos dias 26 de Dezembro de 2010, às $18 \mathrm{~h} 00$ e para o dia 21 de Fevereiro às $15 \mathrm{~h} 00$.

Como pode ser observado na Figura 9 e na Figura 10, há alteração significativa da altura da onda à medida que a onda se propaga em direçấo a zona de praia, para todos os períodos em estudo, devido ao efeito da refração das ondas. Os resultados das propagaçóes assemelham-se em ambos os casos, no que se refere à $\mathrm{Hs}$ e Tmed, quando entra nas profundidades abaixo de $10 \mathrm{~m}$, incidindo paralelamente junto à costa, com direçóes predominantes de $40^{\circ}$ no PT1 (NE), e $50^{\circ}$ e $350^{\circ}$ no PT2 (NE), respectivamente.

Em relação ao período médio durante a propagação da agitação incidente os períodos de $3.8 \mathrm{~s}$ e $4.5 \mathrm{~s}$ são os mais frequentes em relação no espaço, respectivamente.
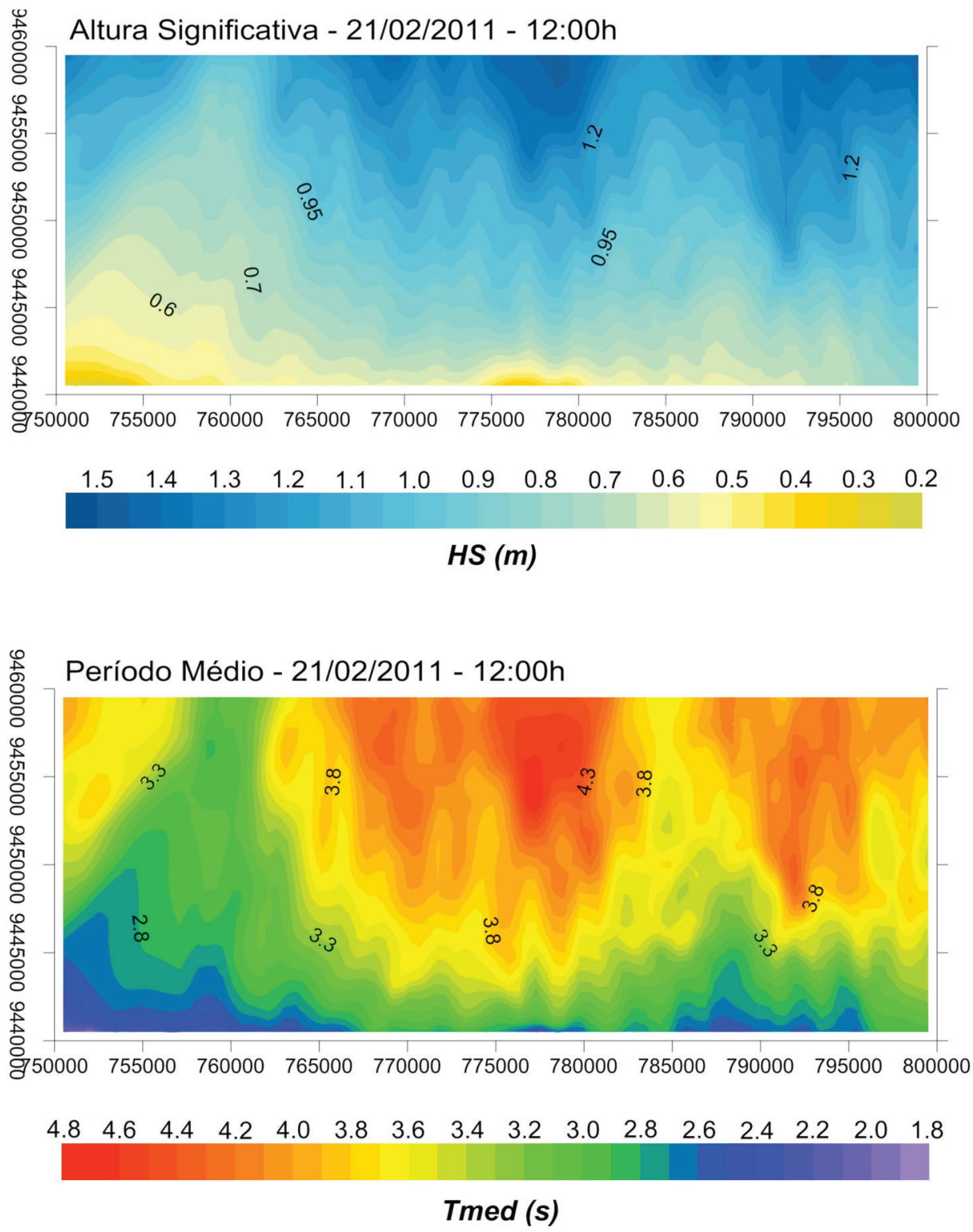

Figura 9. Resultado da simulação do modelo SWAN do dia 21 de Fevereiro de 2011, às 12:00h, para as alturas de ondas significativas (HS), período médio (Tmed) e direçâo média (DIRmed).

Figure 9. Results of SWAN significant heights (HS), mean period (Tmed) and mean wave direction (DIRmed) for day 21 February 2011, 12:00h. 

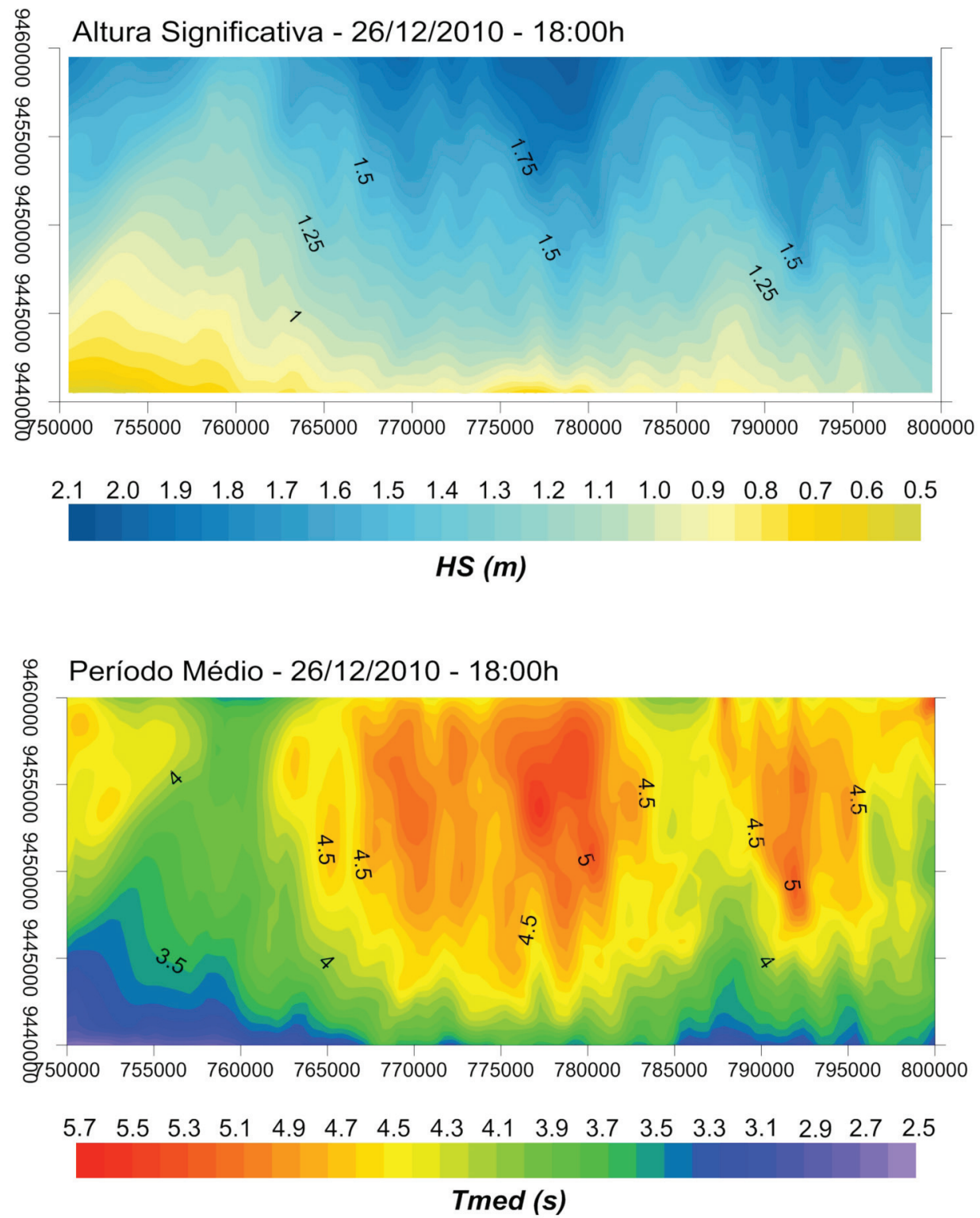

Figura 10. Resultado da simulação do modelo SWAN do dia 26 de Dezembro de 2010, às 18:00h, parar as alturas de ondas significativas (HS), período médio (Tmed) e direção média (DIRmed).

Figure 10. Results of SWAN significant wave heights (HS), mean period (Tmed) and mean direction (DIRmed) from 26 December 2010, 18:00h.

\section{COMPARAÇÁO DE RESULTADOS OBTIDOS PELO MODELO NUMÉRICO E MEDIÇÓES IN SITU}

Nesta seção, são apresentados os resultados das simulaçôes feitas com o SWAN (formulação KOMEN, com o coeficiente de atrito $0.015 \mathrm{~m}^{2} \mathrm{~s}^{-3}$ em regime estacionário) com as aplicaçóes das formulaçóes padróes e diferentes variáveis físicas, as que obtiveram melhor ajustamento foram às simulaçôes para os períodos médios, tanto nas simulaçóes para o período de 20 a 27 de Dezembro de 2010 como de 15 a 22 de Fevereiro de 2011.

Os resultados numéricos e os baseados nas medidas in situ relativos à altura de onda significativa, período médio e direção média, HS, Tmed e DIRmed, são devidamente comparados nos pontos PT1 e PT2 para avaliar o desempenho do modelo SWAN (Figuras 11 a 16).

Para uma melhor análise, os dados das mediçóes in situ e os valores numéricos para as alturas significativas foram submetidos a uma avaliação estatística. $\mathrm{Na}$ Tabela 4 são apresentados os valores do Viés, da média do erro percentual absoluto (MAPE), do valor erro médio quadrático (RMSE) e do índice de concordância ou reajuste, representado pela letra "d" (Wilmott, 1981), que permitem avaliar quantitativamente e estatisticamente a concordância entre os valores medidos e os valores estimados numericamente pelo 
modelo. Os seus valores variam desde zero, onde náo existe concordância, a 1, a concordância é perfeita, ou seja, menor a escala de erros. O índice de Wilmott é assim descrito:

Média do Erro Percentual Absoluto - MAPE (Mean Absolute Percentual Error)

$$
M A P E=\frac{100}{N} \sum_{i=1}^{n} \frac{\left|\left(O_{i}-P_{i}\right)\right|}{O_{i}}
$$

Erro Médio Quadrático - RMSE (Root Mean Square Error)

$$
R M S E=\sqrt{\frac{1}{N} \sum_{i=1}^{n}\left(O_{i}-P\right)^{2}}
$$

Índice de Concordância “d” (Willmott, 1981)

$$
d=1-\frac{\sum_{i=1}^{n}\left(O_{i}-P_{i}\right)^{2}}{\sum_{i=1}^{n}\left(\left|P_{i}-\bar{O}\right|+\left|O_{i}-\bar{O}\right|\right)^{2}}
$$

onde, d é o índice de concordância, $O$ são os valores medidos, $P_{i}$ são os valores dos modelos numéricos, $o$ é o erro da medida do valor experimental e $n$ é o número de observaçóes. Este índice varia de 0 a 1 , sendo que quanto mais próximo do 1 , menor será a escala de erros.

Conclui-se que no geral o modelo conseguiu representar razoavelmente bem a evolução da onda desdeao largo até a zona de praia. Das análises estatísticas para as alturas significativas, embora se observe semelhança no comportamento, o índice de concordância entre eles, mostrou-se abaixo de 0.5. Em ambos os casos, em comparação com as observaçóes houve semelhança no comportamento das alturas significativas e períodos médios, apesar de os valores medidos mostraremse sempre superiores aos valores numéricos. No entanto, verificou-se para a estação do PT1 que o modelo conduz a resultados numéricos mais próximos dos medidos, este em menor profundidade.

Dos resultados acima apresentados, pode constatar-se que, para o PT1, no geral, o andamento e a ordem de grandeza dos valores de altura de onda e período médio, calculados pelo modelo numérico SWAN, apresentam comportamentos semelhantes aos correspondentes dos valores medidos, o mesmo se dá para os períodos médios. No entanto os valores diferem e a concordância é inferior a 0,5 conforme a tabela 4 .

Para as alturas de onda significativas e para o período em análise houve maior frequência para ondas de alturas de ondas significativas de $1.04 \mathrm{~m}$ (SWAN) e de $0.87 \mathrm{~m}$ (IN SITU). Verifica-se que os valores numéricos apresentam ligeira superioridade em relação aos medidos, até o dia 18/02/2011, passando entre os dias 19-20/02/2011 a serem mais próximos dos valores medidos. A partir dessa data decaem bruscamente em relação aos valores medidos, principalmente no dia 21 , quando os valores numéricos aproximam-se da menor altura calculada observada, $0.03 \mathrm{~m}$ enquanto os valores medidos se aproximam de $1.13 \mathrm{~m}$.

Quanto aos valores dos períodos médios, verificou-se maior frequência para as ondas com períodos médios de 4.78 s (SWAN) e de 4.45 s (IN SITU). Nota-se que os valores dos dados medidos são maiores em relação aos numéricos ao longo de todos os dias das análises, principalmente nos dias 20-21/02/2011.

Em relação às direções médias, o modelo não conseguiu reproduzi-las: os valores são sempre inferior aos medidos, são mais constantes as frequências de $15^{\circ}$ e $17^{\circ}$, predominante de NE, enquanto que os medidos são mais dispersos ao longo dos dias, predominando ondas com direçóes entre $195^{\circ}$ a 244ㅇ, SW e NW. Pressupóem-se que a diferença em relação às direçôes esteja mais inserida nos dados medidos, devido este ponto estar em uma zona próxima da ilha barreira, apresentando uma batimetria marcada por bancos arenosos paralelos e longitudinais à costa com influência de correntes de marés, sugerindo propagação de direções de ondas sem padróes ao longo dos dias, o que é sub-estimado nos valores obtidos pelo modelo numérico.

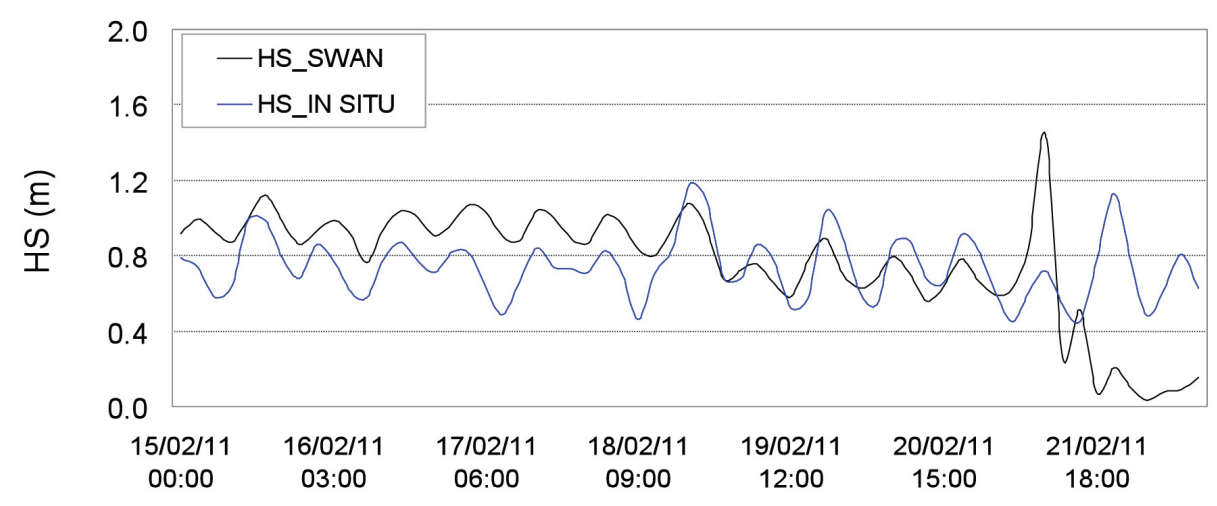

Figura 11. Comparação dos resultados da altura significativa da onda obtidos com o SWAN e com as mediçóes in situ para o PT1.

Figure 11. Comparison of results of the significant wave height obtained with SWAN and for in situ measurements PT1. 


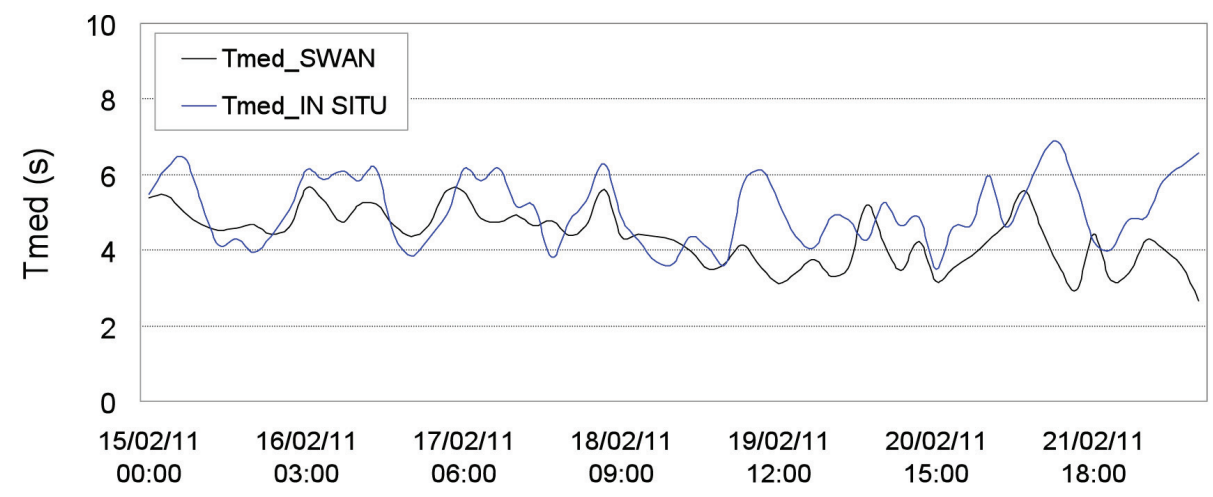

Figura 12. Comparação dos resultados do período médio da onda obtidos com o SWAN e com as mediçóes in situ para o PT1.

Figure 12. Comparison between the mean wave period results obtained with the wave SWAN and for in situ measurements PT1.

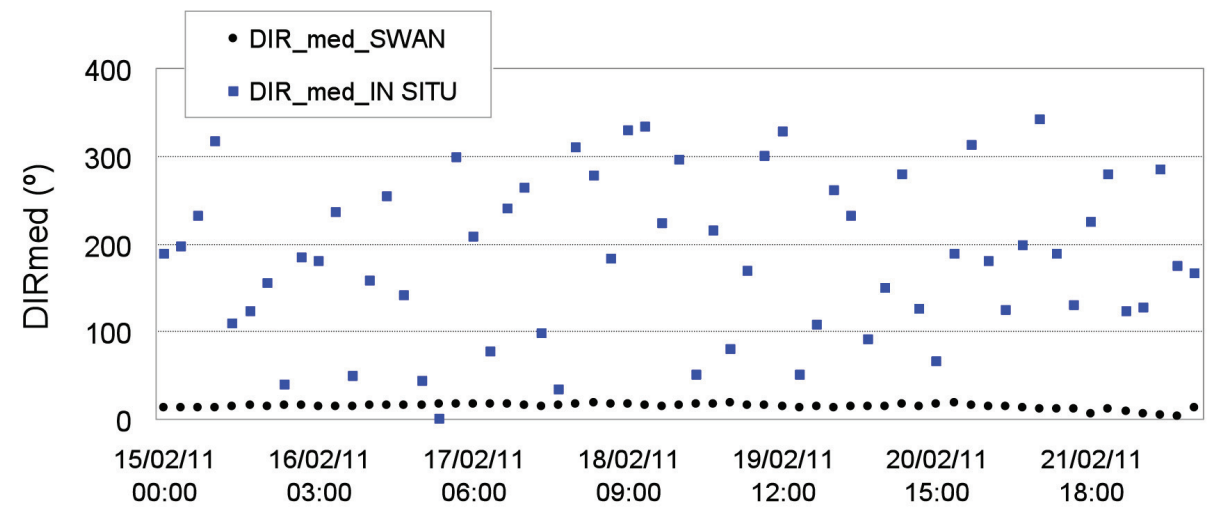

Figura 13. Comparação dos resultados das direçôes médias obtidos com o SWAN e com as mediçóes in situ para o PT1.

Figure 13. Comparison of the results of mean directions obtained with SWAN and in situ measurements for the PT1.

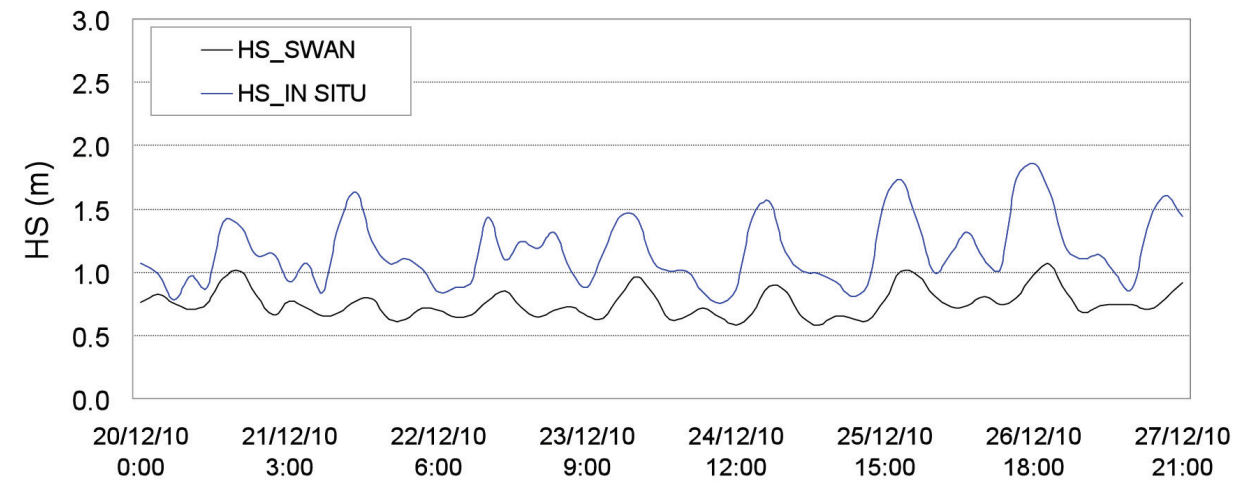

Figura 14. Comparação dos resultados da altura significativa da onda obtidos com o SWAN e com as mediçóes in situ para o PT2.

Figure 14. Comparison between SWAN significant wave height results and in situ measurements PT2. 


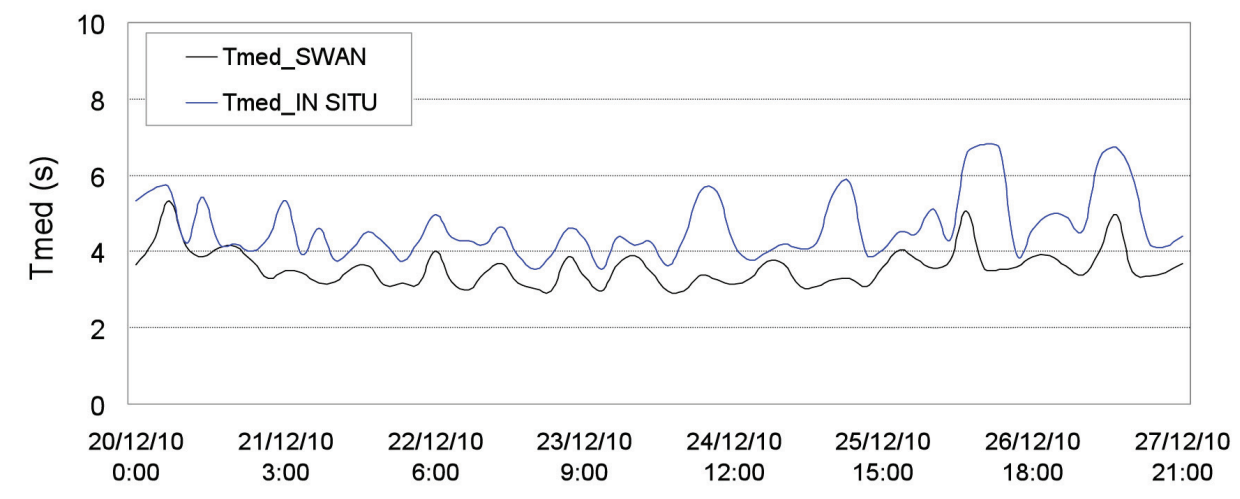

Figura 15. Comparação dos resultados do período médio obtidos com o SWAN e com as mediçóes in situ para o PT2.

Figure 15. Comparison between SWAN significant wave period results and in situ measurements PT2.

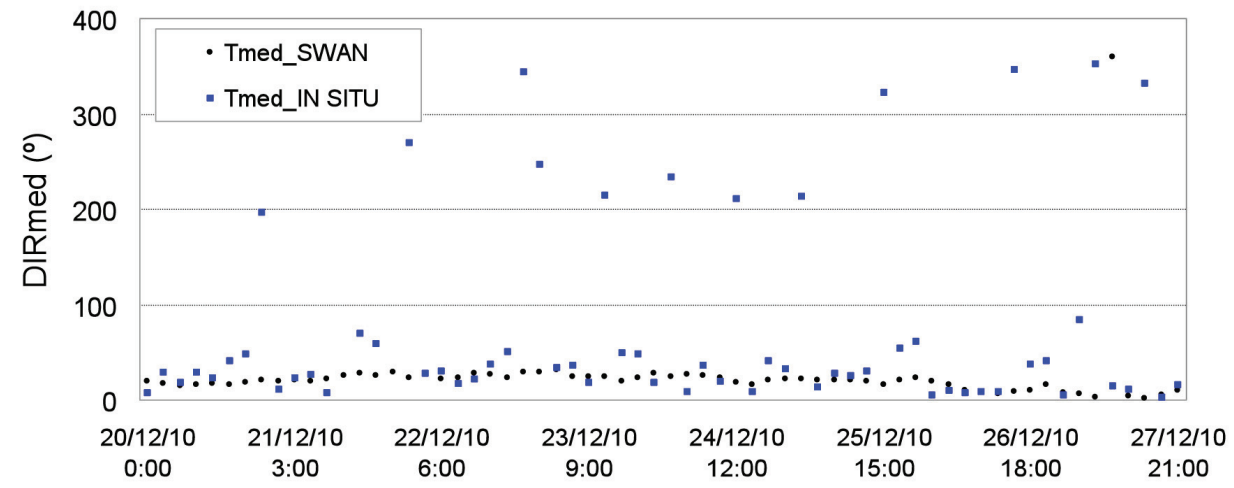

Figura 16. Comparação dos resultados das direções médias da onda obtidos com o SWAN e com as mediçóes in situ para o PT2.

Figure 16. Comparison of the results of mean directions obtained with SWAN and in situ measurements for the PT2.

Para o PT2, também o andamento geral e a ordem da grandeza dos valores de altura de onda significativa e período médio calculado pelo modelo numérico SWAN são semelhantes aos correspondentes valores medidos. De modo geral, o SWAN simula bem os valores de altura e período de onda, embora os valores sejam, em geral, inferiores do que os medidos e as diferenças sejam da ordem de 0.41 hs e $1.1 \mathrm{~s}$.

Em relaçáo às alturas de ondas, os resultados do modelo (SWAN) mostraram maior frequência de ondas entre 0.70 $\mathrm{m}$ e $0.76 \mathrm{~m}$, enquanto que nos valores medidos (IN SITU) a maior frequência foi entre $1,03 \mathrm{~m}$ e $1.17 \mathrm{~m}$, evidenciando que os valores medidos foram superiores aos numéricos durante todos os dias em análise.

Nos períodos médios, o mesmo ocorre, com superioridade dos valores medidos em relação aos valores numéricos, com maior frequência de ondas de períodos médios de $3.25 \mathrm{~s}$ (SWAN) e 4.35 s (IN SITU).
Nas direçôes médias os valores medidos continuam superiores aos numéricos, contudo, demonstra uma característica de direçóes médias com padróes predominantemente de NE, próximo dos padróes numéricos, com frequências de $20^{\circ}-27^{\circ}$ (SWAN) e $46^{\circ}$ (IN SITU). Assim como para o PT1, as direções médias desta estação ao longo de toda análise foi mal sucedido devido o fato das mediçôes dos ventos ter sido efetuada em terra.

Das análises obtidas das estatísticas para as alturas significativas de ondas, períodos médios e direçóes médias notam-se que os parâmetros estatísticos são consideravelmente baixo como sugere o índice de concordância, $d$, indicando boa aproximação. Nas tabelas 4 e 5 constata-se que a simulação que apresentou melhor indicador estatístico, foram os períodos médios, para ambos os períodos. 
Tabela 4. Parâmetros estatísticos da agitação marítima de 15 a 22 de Fevereiro (PT1).

Table 4. The statistical parameters of agitation sea from 15 to 22 February.

\begin{tabular}{llll}
\hline Parâmetro & \multicolumn{1}{c}{ Hs $(\mathbf{m})$} & \multicolumn{1}{c}{ Tmed $(\mathbf{s})$} & \multicolumn{1}{c}{ Dir (graus) } \\
\hline MAPE & 33.3408 & 17.6438 & 249.3527 \\
\hline RMSE & 0.3024 & 1.2380 & 193.4054 \\
\hline$d$ & 0.4818 & 0.5177 & 0.4039 \\
\hline
\end{tabular}

Tabela 5. Parâmetros estatísticos da agitação marítima de 20 a27 de Dezembro (PT2).

Table 5. The statistical parameters of agitation sea from 20 on 27 December (PT2).

\begin{tabular}{llll}
\hline Parâmetro & Hs $(\mathbf{m})$ & \multicolumn{1}{c}{ Tmed $(\mathbf{s})$} & \multicolumn{1}{c}{ Dir (graus) } \\
\hline MAPE & 33.2312 & 21.6706 & 103.2984 \\
\hline RMSE & 0.4612 & 1.2830 & 135.1310 \\
\hline $\mathrm{d}$ & 0.4914 & 0.5242 & 0.4039 \\
\hline
\end{tabular}

\section{CONCLUSÓES}

Neste trabalho, são apresentadas as medições da agitação marítima e os resultados da aplicação do modelo SWAN na zona marítima do Litoral Setentrional do Rio Grande do Norte, nordeste do Brasil, com vista a caracterizar o padrão de ondas geradas pelo vento em diferentes condiçôes de agitação incidente.

O modelo SWAN é assim aplicado na propagação de várias condiçóes de agitação incidente desde o largo até junto à costa da área adjacente ao estuário de Diogo Lopes. Mais concretamente, o modelo foi aplicado para dois períodos, 20 a 27 de dezembro de 2010 e 15 a 22 de fevereiro de 2011, períodos das mediçóes in situ e considerando as condiçóes de agitaçáo marítima ao largo fornecida pelo modelo de previsão WAVEWATCH III (Tolman, 1999; 2002). Para os esses períodos é executado o modelo SWAN e obtidas as características da agitação marítima neste segmento do litoral. Seguidamente, efetuou-se a comparação das características da agitação obtidas com os resultados numéricos e os dados medidos nos instrumentos colocados para o efeito em profundidades entre 5 e $8 \mathrm{~m}$, em momentos de regime de meso-marés (marés semi-diurnas em fase de sizígia).

Da comparação entre dados medidos e simulaçôes numéricas, pode-se concluir que SWAN é um modelo que conseguiu, em geral, representar a evolução das alturas de onda significativas, períodos médios da onda e direçóes médias, especialmente para o ponto que se situa mais ao largo. No entanto, para estas grandezas, os valores numéricos são em geral mais alisados e na maioria dos casos inferiores aos medidos.

Em relação à direção de onda, o modelo apresenta maiores dificuldades na simulação dos valores medidos.
O modelo não consegue simular a vasta gama de direçóes presente nos dados medidos, especialmente para o ponto PT1, mais próximo da costa, onde efeitos de correntes e ventos locais variam mais significativamente. $\mathrm{O}$ modelo conduz a resultados numéricos mais próximos dos medidos para o ponto em maiores profundidades, PT2.

As diferenças encontradas entre os resultados numéricos e os medidos, especialmente para as simulações das direçōes médias, são devidas às simplificaçôes que tiveram de ser admitidas na execução dos cálculos, por falta de informação, nomeadamente no que diz respeito aos ventos (ventos constantes em todo o domínio computacional e baseados nos valores obtidos na estação meteorológica continental), e às correntes (não foram incluídas nos cálculos as correntes).

Assim, a caracterizaçáo dos campos de ventos e de correntes na zona e sua inclusão nas simulações numéricas ao longo dos períodos de simulação, bem como a inserção de mais séries temporais, configuram-se na continuidade do trabalho. Apesar de ter ocorrido baixa concordância, $d$, com os dados, mostrou boa aproximação entre eles, especialmente nas simulaçóes feitas para os períodos médios.

Conclui-se que as simulações feitas com o SWAN (formulaçáo KOMEN, com o coeficiente de atrito 0.015 $\mathrm{m}^{2} \mathrm{~s}^{-3} \mathrm{em}$ regime estacionário) assumindo as formulaçóes padróes e diferentes variáveis físicas, que obtiveram melhor ajustamento foram as simulaçóes para os períodos médios, tanto nas simulaçóes para o período de 20 a 27 de Dezembro de 2010 como de 15 a 22 de Fevereiro de 2011.

E por fim, conclui-se que o modelo SWAN conseguiu prever as condiçóes de ondas no Litoral Setentrional do Rio Grande do Norte, uma área de abrangência regional de aproximadamente $300 \mathrm{~km}^{2}$ de extensão.

\section{AGRADECIMENTOS}

Os autores agradecem a fonte financiadora brasileira CAPES, pela concessão da bolsa através da Rede Amigos Boussinesq; à Fundação para Ciência e Tecnologia (FCT) pelo financiamento concedido através dos Projetos PTD/ECM/73145, PTD/AMB/67450/2006 e PTDC/ECM/67411/2006 e aos projetos cooperativos HIDROSEMA e MOLECO, da Rede de Monitoramento: REDE5-PETROMAR/CTPETRO-FINEP/PETROBRAS/ CNPq. Às equipes de trabalho do Departamento de Geologia, da Universidade Federal do Rio Grande do Norte - GEOPRO/DG/UFRN e Núcleo de Portos e Estruturas Marítimas - NPE/DHA/LNEC de Portugal.

\section{REFERÊNCIAS BIBLIOGRÁFICAS}

Ângelo, J.S.F.C. (2012) - Aplicação do SWAN na caracterização da agitação marítima na zona adjacente ao Estuário de Diogo Lopes, Brasil. 79p. Dissertação de Mestrado, Instituto Técnico de Lisboa, Lisboa, Portugal. Não publicado.

BooijJ, N.; Ris, R.C. Holthuijsen, L.H. (1999) - A thirdgeneration wave model for coastal regions, Part I, Model description and validation. Journal Geophysical Research, 104(C4):7649-7666. DOI: 10.1029/98JC02622.

Boori. M.S.; Amaro, V.E. (2010) - Land use change detection for environmental management: using multi-temporal 
satellite data in the Apodi Valley of northeastern Brazil. Applied GIS (ISSN: 1832-5505), 6(2):1-15, Monash University, Melbourne, Australia.

Caldas, L.H.O. (2002) - Late Quaternary coastal evolution of the northern Rio Grande do Norte coast, NE Brazil. PhD Thesis, 92p., Kiel University, Germany, Unpublished.

Chaves, M. S. (2005) - Dinâmica costeira da área MacauSerra, litoral setentrional do estado do Rio Grande do Norte. Tese de Doutorado, 97p., Universidade Federal do Rio Grande do Norte, Natal, RN, Brasil. Não publicado. Disponível em http://bdtd.bczm.ufrn.br/tde_buscal arquivo.php? codArquivo=331.

Davis Jr., R.A. (1985) - Coastal sedimentary environments. 716p.. Springer-Verlag, New York, USA. ISBN: 9780387960975.

Dean, R.G.; Darlymple, R.A. (2001) - Coastal processes: with engineering applications. 489p.. Cambridge University Press, Cambridge, U. K. ISBN: 9780511754500.

Ferreira, A.T.S.; Amaro, V.E.; Santos, M.S.T.; Santos, A.L.S. (2012) - Estimativa de parâmetros de ondas oceânicas através de sensores ópticos passivos de alta resolução. Revista de Geologia (ISSN 0103-2410), SI 25: 20-36, Fortaleza, CE, Brasil,

Fonseca, V.P. (1996) - Estudo morfo-neotectônico na área do baixo curso do Rio Açu (Assu-Macau), Rio Grande do Norte. Dissertação de Mestrado, 109p., Instituto de Geociências, Universidade Federal de Minas Gerais, Belo Horizonte, MG, Brasil. Não publicado.

Fortes, C.J.E.M.; Pinheiro, L.; Palha, A. (2007) - O pacote de dados SOPRO 3.1: evoluçóes recentes, Atas das $5^{\text {as }}$ Jornadas Portuguesas de Engenharia Costeira e Portuária, Lisboa, Portugal.

Fortes, C.J.E.M.; Matos, M.F.A.; Scudelari, A.C.; Amaro, V.E. (2011) - Caracterização da agitação marítima nas proximidades da Ponta do Tubarão - RN, Nordeste do Brasil. Atas do $6^{\circ}$ Congresso sobre Planeamento e Gestão das Zonas Costeiras dos Paises de Expressão Portuguesa, pp 71 (versão eletrónica), APRH / AIPCN/PIANC, Boa Vista, Cabo Verde.

Góis, D.M.M. (2008) - Estudo da circulação hidrodinâmica $e$ da dispersáo de óleo na zona costeira entre Macau e Galinhos. Dissertaçáo de Mestrado, 115p., Universidade Federal do Rio Grande do Norte, Natal, RN, Brasil. Não publicado. Disponível em http://bdtd.bczm.ufrn. br/tde_arquivos/32/TDE-2009-07-13T111717Z-2141/ Publico/DanielMMG_capa_ate_cap5.pdf.

Gomes, M. P. (2009) - Aquisição, processamento e análise de dados de sísmica de alta resoluçáo na Plataforma Continental Norte do Rio Grande do Norte: Vale inciso do Rio Açu. Dissertação de Mestrado, 125p., Universidade Federal do Rio Grande do Norte, Natal, RN, Brasil. Não publicado. http://ftp.ufrn.br/pub/biblioteca/ext/bdtd/MoabPG.

Griggs, G.B.; Trenhaile, A.S. (1994) - Coastal cliffs and platforms. In: R. W. G. Carter \& C. D. Woodroffe, (eds), Coastal Evolution: Late Quaternary Shoreline Morphodynamics. pp.425-476, Cambridge University Press, Cambridge, United Kingdom. ISBN: 100521598907.

Grigio, A.M., Amaro, V.E., Vital, H., Diodato, M.A. (2005) - A method for coastline evolution analysis using GIS and Remote sensing - A case study from the Guamare city, Northeast Brazil. Journal of Coastal Research (ISSN 0749-0208), SI 42: 412-421, West Palm Beach, FL, USA,

Hasselmann, K.; Barnett, T.P.; Bouws, E.; Carlson, H.; Cartwright, D.E.; Enke, K.; Ewing, J.A.; Gienapp, H.; Hasselmann, D.E.; Kruseman, P.; Meerburg, A.; Miller, P.; Olbers, D.J. Richter, K.; Sell, W.; Walden, H. (1973) - Measurements of wind wave-growth and swell decay during the joint North Sea Wave Project (JONSWAP). Ergänzungsheft zur Deutschen Hydrographischen Zeitschrift . Reihe A(8), no. 12, 95p., Deutsches Hydrographisches Institut, Hamburg, Germany. Disponível em http:// repository.tudelft.nl/view/hydro/uuid\%3Af204e18813b9-49d8-a6dc-4fb7c20562fc/

Hauser, D.; Khama, K.; Krogstad, H.E.; Lehner, S.; Jaak, A.J.; Monbaliu, J.; Wyatt, L.R. (eds.) (2005) - Measuring and analysing directional spectra of ocean waves. $485 \mathrm{p}$., COST Action 714, EUR 21367, Brussels, Belgium. ISBN: $92-$ 89800038. Disponível em http://hal.archives-ouvertes. fr/docs/00/52/97/55/PDF/QSNA21367ENC_002.pdf

Leite F.S. (2007) - Transporte e dispersão de uma pluma de gás natural no oceano: caracterização experimental $e$ modelagem matemática. Tese de Doutorado, $167 \mathrm{p}$., Universidade Federal de Pernambuco, Recife, PE, Brasil. Não publicado.

Lima, Z.M.C.; Alves, A.L.; Amaro, V.E.; Vital, H. (2001) Evoluçáo da linha de costa do esporão de Galinhos-RN usando fotografias aéreas e imagem Landsat. Pesquisas em Geociências (ISSN: 1518-2398), 28(2):497-507, Universidade Federal do Rio Grande do Sul, Porto Alegre, RS, Brasil.

Lima, Z.M.C.; Vital, H.; Tabosa, W.F. (2006) Morphodynamic variability of the Galinhos Spit, NE Brazil. Journal of Coastal Research (ISSN 0749-0208), SI39:598-601. Disponível em http://www.cerf-jcr.org/ images/stories/119_lima.pdf.

Marques, F.M.S.F. (1997) - As Arribas do Litoral do Algarve: Dinâmica, processos e mecanismos. Tese de Doutoramento, 549p., Universidade de Lisboa, Lisboa, Portugal. Não publicado.

Matos, M.F.A.; Fortes, C.J.E.M.; Amaro, V.E.; Scudelari, A.C. (2011) - Análise de dados a partir de métodos in situ no litoral setentrional do Rio Grande do Norte. VI Congresso sobre Planeamento e Gestão das Zonas Costeiras dos Países de Expressão Portuguesa, pp 73 (versão eletrónica), APRH / AIPCN/PIANC, Boa Vista, Cabo Verde.

Matos, M.F.A.; Amaro, V.E. (2011) - Oscillatory Coastal Wave and Currents Profile in the Northern Continental Shelf of Rio Grande do Norte State, Northeast Brazil. Proceedings of the 5th International Geoscience Programme, Conference, Continental Shelves: Risks, Resources and Record of the Pats. UNESCO/IUGS, pp.48-55, Sidney, British Columbia, Canadá. Disponível em http://inovageo.eco. br/files/arquivos/7L233ten1Y32ze9I5c25.pdf

Pedersen, T.; Siegel, E.; Wood, J. (2007) - Directional wave measurements from a subsurface buoy an acustic wave and current profile (AWAC), Oceans 2007 Vancouver, 10p., MTS/IEEE, Vancouver, British Columbia, Canadá. Disponível em http://www.nortekusa.com/lib/ bibliography/oceans-2007-vancouver-suv. 
Rios, V.P.L.; Amaro, V.E. (2012) - Caracterização de depósitos sedimentares holocênicos no sistema de Ilhas Barreiras do Estuário de Diogo Lopes, Litoral Setentrional do Rio Grande do Norte. Revista de Geologia (ISSN: 0103-2410), SI 25:55-69, Fortaleza, Ceará, Brasil,

Rocha, M.V.L.; Moura, T.; Fortes, C.J.E.M.; Capitão, R.; Bezerra, M.M.; Sancho, F.E. (2012) - Análise comparativa de mediçóes in situ e estimativas numérica na Praia da Cornélia, Costa da Caparica, Portugal. Revista de Gestão Costeira Integrada, 12(2):147-157. DOI: 10.5894/ rgci303.

Scudelari, A.C.; Fortes, C.J.E.M.; Dantas, A.L.S.S. (2007) Propagação da agitação marítima na regiáo de GalinhosGuamaré, Rio Grande do Norte, Brasil. Congresso Ibero Latino-Americano sobre Métodos Computacionais em Engenharia, pp.1-18, CMNE/CILANCE, Porto, Portugal.

Scudelari, A.C.; Fortes, C.J.E.M.; Neves, C.F. (2011) - Determining the nearshore wave climate between Galinhos and Guamaré, Brazil. Journal of Coastal Research (ISSN 0749-0208), Szczecin, Polónia, SI 64:1179-1183. Disponível em http://www.ics2011.pl/artic/SP64_11791183_A.C.Scudelari.pdf.

Silveira, I.M. (2002) - Monitoramento Geo-ambiental da Região Costeira do Município de Guamaré-RN. Dissertação de Mestrado, 161p., Universidade Federal do Rio Grande do Norte, Natal, Brasil. Não publicado. Disponível em http://bdtd.bczm.ufrn.br/tde_busca/ arquivo.php?codArquivo=257.

Souto, M.V.S.; Grigio, A.M.; Castro, A.F.; Amaro, V.E. (2006) - Multitemporal analysis of geonvironmental elements of the coastal dynamics of the region of the Ponta do Tubarão, City of Macau/RN, on the Basis is remote sensing products and integration in GIS. Journal of Coastal Research (ISSN 0749-0208), SI 39:16181621.

Suguio, K. (2003) - Geologia Sedimentar. 400p., Editora Edgard Blücher, São Paulo, SP, Brasil. ISBN: 8521203179.
Summerfield, M.A. (1991) -Global Geomorphology: an introduction to the study of landforms. $537 \mathrm{p}$., Longman Scientific \& Technical, London, U.K. ISBN: 9780470216668.

Tabosa, W.F.; Vital, H.; Amaro, V.E. (2002) - Morphologic and structural characterization of the Rio Grande do Norte State, NE Brazil, based on remote sensing images. Annual Meeting of American Association of Petroleum Geologist, 6p., AAPG, Houston, TX, U.S.A. Disponível em http://www.searchanddiscovery.com/abstracts/ pdf/2002/annual/EXTENDED/ndx_43377.pdf

Tolman, H.L. (1999) - User manual and system documentation of WAVEWATCH - III Version 1.18. NOAA - National Oceanic and Atmospheric Administration, Technical Note 166, 110p., Washington, DC, U.S.A. Disponível em http://polar.ncep.noaa.gov/mmab/papers/tn166/ OMB_166.pdf.

Tolman, H.L. (2002) - User manual and system documentation of WAVEWATCH - III Version 2.22. NOAA - National Oceanic and Atmospheric Administration,Technical Note 222, 133p., Washington, DC, U.S.A. Disponível em http://polar.ncep.noaa.gov/mmab/papers/tn222/ MMAB_222.pdf.

Trenhaile, A.S.; Kanyaya, J.I. (2007) - The role of wave erosion on sloping and horizontal shore platforms in macro- and mesotidal environments. Journal of Coastal Research, 23(2):298-309. DOI: 10.2112/04-0282.1.

Trenhaile, A.S. (2002) - Rock coasts, with particular emphasis on shore platforms. Geomorphology, 48(1-3): 7-22. DOI: 10.1016/S0169-555X(02)00173-3

Willmott, C.J. (1981) - On the validation of models. Physical Geography (ISSN: 0272-3646), 2(2):184-194, Bellwether Publishing, Birmingham, AL, U.S.A. 